\title{
Proteomic Expression Profile in Human Temporomandibular Joint Dysfunction
}

\author{
Andrea Duarte Doetzer ${ }^{1, *}$, Roberto Hirochi Herai ${ }^{1}{ }^{1}$, Marília Afonso Rabelo Buzalaf ${ }^{2}(\mathbb{D}$ and \\ Paula Cristina Trevilatto ${ }^{1}$ \\ 1 Graduate Program in Health Sciences, School of Medicine, Pontifícia Universidade Católica do \\ Paraná (PUCPR), Curitiba 80215-901, Brazil; rherai@gmail.com (R.H.H.); paula.trevilatto@pucpr.br (P.C.T.) \\ 2 Department of Biological Sciences, Bauru School of Dentistry, University of São Paulo, \\ Bauru 17012-901, Brazil; mbuzalaf@fob.usp.br \\ * Correspondence: duarte.andrea@pucpr.br; Tel.: +55-41-991-864-747
}

Citation: Doetzer, A.D.; Herai, R.H.; Buzalaf, M.A.R.; Trevilatto, P.C.

Proteomic Expression Profile in Human Temporomandibular Joint Dysfunction. Diagnostics 2021, 11, 601. https://doi.org/10.3390/ diagnostics11040601

Academic Editor:

Gustavo Baldassarre

Received: 28 February 2021

Accepted: 24 March 2021

Published: 28 March 2021

Publisher's Note: MDPI stays neutral with regard to jurisdictional claims in published maps and institutional affiliations.

Copyright: (c) 2021 by the authors. Licensee MDPI, Basel, Switzerland. This article is an open access article distributed under the terms and conditions of the Creative Commons Attribution (CC BY) license (https:// creativecommons.org/licenses/by/ $4.0 /)$.

\begin{abstract}
Temporomandibular joint dysfunction (TMD) is a multifactorial condition that impairs human's health and quality of life. Its etiology is still a challenge due to its complex development and the great number of different conditions it comprises. One of the most common forms of TMD is anterior disc displacement without reduction (DDWoR) and other TMDs with distinct origins are condylar hyperplasia (CH) and mandibular dislocation (MD). Thus, the aim of this study is to identify the protein expression profile of synovial fluid and the temporomandibular joint disc of patients diagnosed with DDWoR, $\mathrm{CH}$ and MD. Synovial fluid and a fraction of the temporomandibular joint disc were collected from nine patients diagnosed with DDWoR $(n=3), \mathrm{CH}(n=4)$ and MD $(n=2)$. Samples were subjected to label-free nLC-MS/MS for proteomic data extraction, and then bioinformatics analysis were conducted for protein identification and functional annotation. The three TMD conditions showed different protein expression profiles, and novel proteins were identified in both synovial fluid and disc sample. TMD is a complex condition and the identification of the proteins expressed in the three different types of TMD may contribute to a better comprehension of how each pathology develops and evolutes, benefitting the patient with a focus-target treatment.
\end{abstract}

Keywords: temporomandibular joint; protein expression; temporomandibular joint dysfunction

\section{Introduction}

Temporomandibular dysfunction (TMD) is a disorder of the masticatory system and it is characterized by pain, loss of function of one or both articulations, and impairment of the masticatory system. TMD impacts not only jaw function, but the life quality of affected patients, increasing their treatment costs and work absence [1]. According to the National Institute of Health [2], TMD management in the USA costs approximately 4 billion dollars per year. A diagnostic protocol developed for research named Research Diagnostic Criteria for TMD (RDC/TMD), classifies TMD as myalgia, arthralgia, condylar pathologies, disc displacement, osteoarthrosis, osteoarthritis, degenerative joint disease and subluxation [3]. TMD has a multifactorial etiology, the most common being trauma, psychological alterations, hormone, inflammatory diseases, parafunction, and genetics $[1,4]$. TMD usually requires a panorex, and depending on the TMD type, magnetic resonance imaging, scintigraphy and tomography, besides a thorough clinical evaluation $[5,6]$.

Depending on the TMD type, it can be classified as condylar hyperplasia $(\mathrm{CH})$, disc displacement without reduction (DDWoR) and mandibular dislocation (MD). DDWoR is the most common TMD disorder [7], and along with $\mathrm{CH}$, its etiology's understanding is still unclear. MD is a condition that is probably caused by physical alterations [8], and since it is less likely to have hormone contribution, it is a good TMD condition to compare the results with the other pathologies. DDWoR is caused by an abnormal positional association between the disc and the condyle, where the disc is permanently anteriorly displaced 
in relation to the condyle, causing limited range of mouth opening, pain and may lead to temporomandibular joint (TMJ) degeneration [9]. Disc displacement corresponds to $41 \%$ of TMD intra-articular disorders [7], and it is considered a multifactorial disease, with overlapping conditions contributing to its modulation including stress, parafunction, behavioral pattern, emotional status, and genetic background [3]. Among its different types of treatment, clinical handling is firstly employed (splint therapy, medication, physiotherapy) and when unsuccessful, surgery is indicated [6,10]. MD is an involuntary forward movement of the condyle beyond the articular eminence, mostly associated with trauma or excessive mouth opening, impairing its essential functions (speaking, chewing), and it accounts for $3 \%$ of all documented dislocations [11]. It usually needs mechanical manipulation to return to its normal position, and recurrent dislocations require surgical treatment [8]. Between these TMD types, $\mathrm{CH}$ is the rarest pathology that manifests a head condyle overgrowth, causing facial asymmetry, deformity, malocclusion and sometimes pain and dysfunction [12]. It is a self-limiting condition, more prevalent in female teenagers, but it usually requires surgical treatment to limit facial asymmetry progression and condyle continuous elongation [13]. Studies suggest it has a genetic involvement on its development, but its main etiology is still poorly understood [14].

Despite the etiological differences between $\mathrm{CH}, \mathrm{DDWoR}$ and $\mathrm{MD}$, current studies have limited understanding of the molecular variations that differentiates these TMD diseases. Condylar hyperplasia, mandibular dislocation and disc displacement have been the aim of many studies, due to their difficulty in targeting the proper treatment to each disease [9]. The employment of specific treatment, which may be improved with the unveiling of its specific etiology factors, will allow us to diminish treatment time and costs.

At the proteomic level, current studies focus only on individual mandibular dysfunctions, without comparing different TMD types to show the proteomic variability that could drive novel biomarkers as targets for disease diagnostic and treatment [15,16]. Proteomic analysis is a gold standard approach to analyze all identifiable proteins in a certain tissue, investigating its abundance, variety of proteoforms, and their stable or transient proteinprotein interactions. This approach is especially beneficial in the clinical setting when studying proteins involved in different pathologies [17]. To date, there are very few studies investigating human TMD samples through proteomic output, and these studies analyzed only synovial fluid, focusing on specific target proteins $[15,16]$. Therefore, analyzing all proteins present in the synovial fluid and disc sample of different types of TMD may potentially lead TMD treatments towards a new reality.

In this research, a high throughput proteomic investigation of the three TMD pathologies $\mathrm{CH}, \mathrm{DDWoR}$ and $\mathrm{MD}$, was performed. Using state-of-the-art sample extraction procedures, biological samples of synovial fluid and TMJ discs were collected from distinct patients diagnosed with these conditions. The samples were processed, subjected to protein extraction and mass spectrometry proteomic identification. Generated proteomic data were analyzed using bioinformatics methods, and a per-sample protein identification and annotation were performed. The clinical phenotypes were then used to correlate the proteomic profile of each TMD condition.

\section{Materials and Methods}

\subsection{Sample Selection}

The sample was composed of 9 disc and synovial fluid specimens from female patients, with a mean age of 31.22 years (18-52). The patients presented different TMJ conditions, with three samples being composed of TMJ displaced disc without reduction $(n=3)$, two mandibular dislocation $(n=2)$ and four patients with condylar hyperplasia $(n=4)$ (Table 1). The specimens were collected from patients treated at the Evangelic University Hospital of Curitiba, Brazil. The study was approved by the Ethical Committee on Research at Pontifical Catholic University of Paraná, Brazil, according to Resolution 196/96 of the National Health Council and approved on 6 May of 2016 under registration number 1.863.521. 
Table 1. Baseline characteristics of the sample, showing age and pathology of each female patient.

\begin{tabular}{ccc}
\hline Number & Age & Diagnostic \\
\hline 1 & 18 & Condylar Hyperplasia \\
2 & 20 & Condylar Hyperplasia \\
3 & 38 & Mandibular Dislocation \\
4 & 38 & Mandibular Dislocation \\
5 & 36 & Condylar Hyperplasia \\
6 & 29 & Condylar Hyperplasia \\
7 & 25 & Disc Displacement Without Reduction \\
8 & 25 & Disc Displacement Without Reduction \\
9 & 52 & Disc Displacement Without Reduction \\
\hline
\end{tabular}

Subjects did not present any of the following criteria: use of orthodontic appliances; chronic usage of anti-inflammatory drugs; history of diabetes, hepatitis, HIV infection; immunosuppressive chemotherapy; history of any disease known to compromise immune function; pregnancy or lactation; major jaw trauma; previous TMJ surgery; and previous steroid injection in the TMJ.

Subjects answered a personal medical history questionnaire and signed a consent form after being advised of the nature of the study. All patients were clinically examined by one experienced oral and maxillofacial surgeon. The clinical examination consisted of palpating the TMJ region, analyzing the occurrence of painful or limitation/excessiveness of mouth opening/closing, and the observation of facial asymmetry. Regarding complementary exams, all patients had a panorex and patients with disc displacement were submitted to a magnetic resonance image. The patients who were considered to be affected with disc displacement were treated surgically when they presented painful clinical signs of disc displacement after unsuccessful non-surgical treatment for at least 6 months [18]. Patients presenting pain related only to muscular spasms were not included in this research. Patients with condylar hyperplasia were diagnosed through clinical evaluation, panorex and when presenting a positive condylar growth in scintilography, a high condylectomy was indicated and performed [19]. Patients with recidivist mandibular dislocation (more than four episodes in six months) were treated with eminectomy [8].

\subsection{Sample Acquisition}

During access to the TMJ to perform the needed surgery [20], a 21-gauge needle was inserted into the upper TMJ space, then $1 \mathrm{~mL}$ of saline was injected into the joint space, which was aspirated thereafter by a second adapted syringe. This procedure was repeated five times to obtain a synovial fluid sample as described previously by Alstergren [21]. For each type of surgery performed, TMJ disc recontouring and repositioning was needed [16], therefore, first the displaced disc was freed, repositioned and sutured to the latero-posterior side of the condyle with a Mitek bone-cleat. The suture was then placed between the posterior and intermediate bands, and recontouring the thickened disk with a scalpel was necessary (this posterior debrided cartilage constituted the disc sample). Synovial fluid was spun down at $300 \times g$ to remove debris, and stored at $-80^{\circ} \mathrm{C}$ until use or analysis, and the disc samples rinsed in phosphate-buffered saline (PBS), and either snap frozen in liquid nitrogen and stored at $-80^{\circ} \mathrm{C}$.

\subsection{Proteomic Analysis}

The microcentrifuge tubes containing the synovial fluid and TMJ discs were removed from the $-80^{\circ} \mathrm{C}$ freezer, and after defrosting, the discs were cut into small pieces with the aid of sterile scissors, centrifuged, and the supernatants were collected and pooled according to each pathology group. The preparation of the samples for proteomic analysis was carried out as previously reported [22]. The analysis of the tryptic peptides was performed in the nanoACQUITY UPLC system (Waters, Milliford, CT, USA) coupled to the Xevo Q-TOF G2 mass spectrometer (MS) (Waters, Milliford, CT, USA). For this purpose, 
the UPLC nanoACQUITY system was equipped with a column of type HSS T3 (Acquity UPLC HSS T3 column $75 \mathrm{~mm} \times 150 \mathrm{~mm} ; 1.8 \mu \mathrm{m}$, Waters), previously balanced with $7 \%$ of the mobile phase B $(100 \% \mathrm{ACN}+0.1 \%$ formic acid). The peptides were separated through a linear gradient of $7 \%-85 \%$ of the mobile phase B over 70 min with a flow of $0.35 \mu \mathrm{L} / \mathrm{min}$ and the column temperature maintained at $45^{\circ} \mathrm{C}$. The MS was operated in positive ion mode, with a $75 \mathrm{~min}$ data acquisition time. The obtained data were processed using ProteinLynx GlobalServer (PLGS) version 3.03 (Waters, Milliford, CT, USA). Protein identification was obtained using the ion counting algorithm incorporated into the software. The collected data were searched in the database of the species Homo sapiens downloaded from the catalog of the UniProt [23] in September of 2020. The identified proteins for the groups DDWoR, MD, and $\mathrm{CH}$ of synovial fluid and TMJ disc were classified and attributed by biological function, origin, and molecular interaction with the program Genemania [24]. The overlapping proteins between the groups were clustered by using an automatic Venn diagram generator.

\section{Results}

In this qualitative study, our aim was to explore, for the first time, a comparative analysis of the proteomic profile of three distinct TMD diseases. Although a statistical analysis was not performed, we were able to identify and describe the function of the proteins, including overlapping proteins between the investigated samples (DDWoR, MD and $\mathrm{CH}$, and between both synovial fluid and disc samples).

In the synovial fluid samples, a total of 225 proteins ( 351 counting the repeated proteins in all groups) were successfully identified: 190 in the group DDWoR, 154 in the group MD and seven in the group $\mathrm{CH}$. We also compared these three groups to identify shared or condition-specific proteins. We found 114 shared proteins between groups DDWoR and $\mathrm{MD}$, and six proteins were shared by all groups (Table 2 ).

In the disc sample, 379 proteins were identified (697 counting the repeated proteins in all groups), with 235 proteins in group DDWoR, 196 in group MD and 266 in group $\mathrm{CH}$. These three groups were also compared to identify shared or condition-specific proteins. There were nine shared proteins between groups DDWoR and MD, 28 shared proteins between groups DDWoR and $\mathrm{CH}, 17$ shared proteins between groups $\mathrm{MD}$ and $\mathrm{CH}$, and 132 shared proteins by all groups (Table 3 ).

Regarding the proteins in common in both synovial fluid and disc in the same sample groups, DDWoR presented two common proteins, MD presented three proteins, group $\mathrm{CH}$ had no protein in common, and the three groups together had six proteins in common (Table 4).

All synovial fluid and disc samples presented proteins involved in DNA repair, muscle and neural regeneration.

A selective pool of proteins was chosen to be studied according to the pathology group and protein function for synovial fluid and disc sample (Tables 5 and 6).

The synovial fluid sample presented the following proteins functions for each group (Table 5): the DDWoR group presented proteins involved in inflammatory process, apoptosis, hearing, interleukine- 6 cascade, and protection against oxidative stress; the MD group showed proteins involved in inflammatory process, apoptosis, hearing, interleukine-6 cascade, protection against oxidative stress, and immune response; in the $\mathrm{CH}$ group, the expression of alcohol degradation protein (ADH1) was identified. The group comprising the pathologies DDWoR and MD were mainly involved in inflammatory process inhibition, bone resorption, chondrogenesis, bone and cartilage formation, osteoarthrosis, and neuropathic pain. No proteins were observed in the groups DDWoR and $\mathrm{CH}$, and $\mathrm{MD}$ and $\mathrm{CH}$. The proteins expressed in all three groups (DDWoR, $\mathrm{MD}$ and $\mathrm{CH}$ ) were mainly implicated with muscle regeneration. 


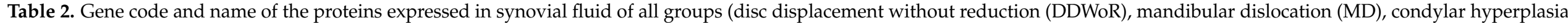
$(\mathrm{CH})$ and between the groups DDWoR and MD, DDWoR and $\mathrm{CH}, \mathrm{MD}$ and $\mathrm{CH}$ and DDWoR, MD and $\mathrm{CH}$.

\begin{tabular}{|c|c|c|c|c|c|c|c|c|c|c|c|}
\hline \multicolumn{12}{|c|}{ Protein Expressed in Each Group of TMJ Synovial Fluid Sample $(n=225)$} \\
\hline \multicolumn{2}{|c|}{ DDWoR $(n=70)$} & \multicolumn{2}{|c|}{ MD $(n=34)$} & \multicolumn{2}{|c|}{$\mathrm{CH}(n=1)$} & \multicolumn{2}{|c|}{ DDWoR and MD $(n=114)$} & \multirow{2}{*}{$\begin{array}{c}\begin{array}{c}\text { DDWoR and } \\
\text { CH }(n=0)\end{array} \\
\mathrm{X}\end{array}$} & \multirow{2}{*}{$\begin{array}{c}\begin{array}{c}\text { MD and } \mathrm{CH} \\
(n=0)\end{array} \\
\mathrm{X}\end{array}$} & \multicolumn{2}{|c|}{ DDWoR, MD and CH $(n=6)$} \\
\hline Code & Name & Code & Name & Code & Name & Code & Name & & & Code & Name \\
\hline ANXA5 & Annexin A5 & ACTR3C & Actin Related Protein 3C & & & ACTA1 & $\begin{array}{l}\text { Actin Alpha 1, } \\
\text { Skeletal } \\
\text { Muscle }\end{array}$ & & & ENO2 & Enolase 2 \\
\hline APCS & $\begin{array}{l}\text { Amyloid P } \\
\text { Component }\end{array}$ & AKNA & $\begin{array}{c}\text { AT-Hook Transcription } \\
\text { Factor }\end{array}$ & & & ACTA2 & $\begin{array}{l}\text { Actin Alpha 2, } \\
\text { Smooth } \\
\text { Muscle }\end{array}$ & & & ENO3 & Enolase 3 \\
\hline $\mathrm{APOH}$ & Apolipoprotein $\mathrm{H}$ & ALDH1L1 & $\begin{array}{c}\text { Aldehyde } \\
\text { Dehydrogenase } 1 \text { Family } \\
\text { Member L1 }\end{array}$ & & & АСТВ & Actin Beta & & & MYH16 & $\begin{array}{l}\text { Myosin Heavy } \\
\text { Chain } 16 \\
\text { Pseudogene }\end{array}$ \\
\hline ARHGAP21 & $\begin{array}{l}\text { Rho GTPase } \\
\text { Activating } \\
\text { Protein } 21\end{array}$ & $\mathrm{C} 4 \mathrm{~A}$ & $\begin{array}{c}\text { Complement C4A } \\
\text { (Rodgers Blood Group) }\end{array}$ & & & ACTBL2 & $\begin{array}{l}\text { Actin Beta } \\
\text { Like } 2\end{array}$ & & & RPL7L1 & $\begin{array}{l}\text { Ribosomal } \\
\text { Protein L7 } \\
\text { Like 1 }\end{array}$ \\
\hline $\mathrm{CFH}$ & $\begin{array}{l}\text { Complement } \\
\text { Factor H }\end{array}$ & C4B_2 & $\begin{array}{l}\text { Complement } \\
\text { Component } 4 \mathrm{~B}\end{array}$ & & & АСТC1 & $\begin{array}{l}\text { Actin Alpha } \\
\text { Cardiac } \\
\text { Muscle } 1\end{array}$ & & & SHLD3 & $\begin{array}{l}\text { Shieldin } \\
\text { Complex } \\
\text { Subunit } 3\end{array}$ \\
\hline CHD8 & $\begin{array}{l}\text { Chromodomain } \\
\text { Helicase DNA } \\
\text { Binding Protein } 8\end{array}$ & C7orf57 & Complement C7 & & & ACTG1 & $\begin{array}{c}\text { Actin } \\
\text { Gamma } 1\end{array}$ & & & & \\
\hline CILP2 & $\begin{array}{c}\text { Cartilage } \\
\text { Intermediate Layer } \\
\text { Protein }\end{array}$ & CAGE1 & Cancer Antigen 1 & & & ACTG2 & $\begin{array}{l}\text { Actin Gamma } \\
\text { 2, Smooth } \\
\text { Muscle }\end{array}$ & & & & \\
\hline CNOT6L & $\begin{array}{c}\text { CCR4-NOT } \\
\text { Transcription } \\
\text { Complex Subunit } \\
6 \text { Like }\end{array}$ & CPSF2 & $\begin{array}{c}\text { Cleavage And } \\
\text { Polyadenylation Specific } \\
\text { Factor } 2\end{array}$ & & & ALB & Albumin & & & & \\
\hline DAGLA & $\begin{array}{l}\text { Diacylglycerol } \\
\text { Lipase Alpha }\end{array}$ & DCAF4L2 & $\begin{array}{c}\text { DDB1 And CUL4 } \\
\text { Associated Factor } 4 \\
\text { Like } 2\end{array}$ & & & ANXA1 & Annexin A1 & & & & \\
\hline
\end{tabular}


Table 2. Cont.

\begin{tabular}{|c|c|c|c|c|c|c|c|c|c|c|}
\hline \multicolumn{11}{|c|}{ Protein Expressed in Each Group of TMJ Synovial Fluid Sample $(n=225)$} \\
\hline \multicolumn{2}{|c|}{ DDWoR $(n=70)$} & \multicolumn{2}{|c|}{ MD $(n=34)$} & $\mathrm{CH}(n=1)$ & \multicolumn{2}{|c|}{ DDWoR and MD $(n=114)$} & \multirow{2}{*}{$\begin{array}{c}\begin{array}{c}\text { DDWoR and } \\
\text { CH }(n=0)\end{array} \\
\mathrm{X}\end{array}$} & \multirow{2}{*}{$\begin{array}{c}\text { MD and CH } \\
(n=0)\end{array}$} & \multicolumn{2}{|c|}{ DDWoR, MD and CH $(n=6)$} \\
\hline Code & Name & Code & Name & Name & Code & Name & & & Code & Name \\
\hline DPYSL3 & $\begin{array}{l}\text { Dihydropyrimidinase } \\
\text { Like } 3\end{array}$ & DMD & Dystrophin & & ANXA2P2 & $\begin{array}{c}\text { Annexin A2 } \\
\text { Pseudogene } 2\end{array}$ & & & & \\
\hline DYM & Dymeclin & FLNA & Filamin A & & APOA1 & Apolipoprotein A1 & & & & \\
\hline DYNC1H1 & $\begin{array}{c}\text { Dynein } \\
\text { Cytoplasmic } 1 \\
\text { Heavy Chain }\end{array}$ & HPR & $\begin{array}{l}\text { Haptoglobin-Related } \\
\text { Protein }\end{array}$ & & ASPN & Asporin & & & & \\
\hline ENPP3 & $\begin{array}{c}\text { Ectonucleotide } \\
\text { Pyrophosphatase/ } \\
\text { Phosphodiesterase } 3\end{array}$ & HPX & Hemopexin & & ATP5F1B & $\begin{array}{l}\text { ATP Synthase } \\
\text { F1 Subunit } \\
\text { Beta }\end{array}$ & & & & \\
\hline FGFR2 & $\begin{array}{l}\text { Fibroblast Growth } \\
\text { Factor Receptor } 2\end{array}$ & IFT122 & $\begin{array}{l}\text { Intraflagellar Transport } \\
122\end{array}$ & & BGN & Biglycan & & & & \\
\hline GPSM2 & $\begin{array}{l}\text { G Protein Signaling } \\
\text { Modulator } 2\end{array}$ & $\mathrm{LMO} 7$ & LIM Domain 7 & & $\mathrm{C} 3$ & Complement C3 & & & & \\
\hline GPX3 & $\begin{array}{l}\text { Glutathione } \\
\text { Peroxidase } 3\end{array}$ & MYO6 & Myosin VI & & CILP & $\begin{array}{c}\text { Cartilage } \\
\text { Intermediate } \\
\text { Layer Protein }\end{array}$ & & & & \\
\hline GSTP1 & $\begin{array}{c}\text { Glutathione } \\
\text { S-Transferase Pi } 1\end{array}$ & PDIA3 & $\begin{array}{c}\text { Protein Disulfide } \\
\text { Isomerase Family A } \\
\text { Member } 3\end{array}$ & & CLU & Clusterin & & & & \\
\hline $\mathrm{H} 2 \mathrm{BC} 1$ & $\begin{array}{l}\text { H2B Clustered } \\
\text { Histone } 1\end{array}$ & PPFIA1 & $\begin{array}{l}\text { PTPRF Interacting } \\
\text { Protein Alpha } 1\end{array}$ & & COL12A1 & $\begin{array}{l}\text { Collagen Type } \\
\text { XII Alpha } \\
\text { 1 Chain }\end{array}$ & & & & \\
\hline H2BE1 & $\begin{array}{l}\text { H2B.E Variant } \\
\text { Histone } 1\end{array}$ & PPFIA2 & $\begin{array}{l}\text { PTPRF Interacting } \\
\text { Protein Alpha } 2\end{array}$ & & COL14A1 & $\begin{array}{l}\text { Collagen Type } \\
\text { XIV Alpha } \\
\text { 1 Chain }\end{array}$ & & & & \\
\hline HSPA1A & $\begin{array}{l}\text { Heat Shock Protein } \\
\text { Family A (Hsp70) } \\
\text { Member 1A }\end{array}$ & PRDX1 & Peroxiredoxin 1 & & COL1A1 & $\begin{array}{l}\text { Collagen Type } \\
\text { I Alpha } 1 \\
\text { Chain }\end{array}$ & & & & \\
\hline
\end{tabular}


Table 2. Cont.

Protein Expressed in Each Group of TMJ Synovial Fluid Sample $(n=225)$

\begin{tabular}{|c|c|c|c|c|c|c|c|c|c|c|c|}
\hline \multicolumn{2}{|c|}{ DDWoR $(n=70)$} & \multicolumn{2}{|c|}{$\operatorname{MD}(n=34)$} & \multicolumn{2}{|c|}{$\mathrm{CH}(n=1)$} & \multicolumn{2}{|c|}{ DDWoR and MD ( $n=114)$} & \multirow{2}{*}{$\begin{array}{c}\text { DDWoR and } \\
\text { CH }(n=0)\end{array}$} & \multirow{2}{*}{$\begin{array}{c}\begin{array}{c}\text { MD and CH } \\
(n=0)\end{array} \\
\mathrm{X}\end{array}$} & \multicolumn{2}{|c|}{ DDWoR, MD and CH $(n=6)$} \\
\hline Code & Name & Code & Name & Code & Name & Code & Name & & & Code & Name \\
\hline HSPA1B & $\begin{array}{c}\text { Heat Shock Protein } \\
\text { Family A (Hsp70) } \\
\text { Member 1B }\end{array}$ & PRDX2 & Peroxiredoxin 2 & & & COL6A1 & $\begin{array}{l}\text { Collagen Type } \\
\text { VI Alpha } \\
1 \text { Chain }\end{array}$ & & & & \\
\hline HSPA1L & $\begin{array}{l}\text { Heat Shock Protein } \\
\text { Family A (Hsp70) } \\
\text { Member } 1 \text { Like }\end{array}$ & RGMB & $\begin{array}{l}\text { Repulsive Guidance } \\
\text { Molecule BMP } \\
\text { Co-Receptor B }\end{array}$ & & & COL6A2 & $\begin{array}{l}\text { Collagen Type } \\
\text { VI Alpha } \\
2 \text { Chain }\end{array}$ & & & & \\
\hline HSPA8 & $\begin{array}{c}\text { Heat Shock Protein } \\
\text { Family A (Hsp70) } \\
\text { Member } 8\end{array}$ & SERPINA9 & $\begin{array}{l}\text { Serpin Family A } \\
\text { Member } 9\end{array}$ & & & COMP & $\begin{array}{l}\text { Thrombospondin- } \\
5\end{array}$ & & & & \\
\hline IGLC1 & $\begin{array}{l}\text { Immunoglobulin } \\
\text { Lambda Constant } 1\end{array}$ & SERPINH1 & $\begin{array}{l}\text { Serpin Family H } \\
\text { Member } 1\end{array}$ & & & $\mathrm{DCN}$ & Decorin & & & & \\
\hline IGLC2 & $\begin{array}{l}\text { Immunoglobulin } \\
\text { Lambda Constant }\end{array}$ & SLC4A1 & $\begin{array}{c}\text { Solute Carrier Family } 4 \\
\text { Member } 1\end{array}$ & & & DES & Desmin & & & & \\
\hline & $\begin{array}{l}\text { Immunoglobulin } \\
\text { Lambda Constant } 6\end{array}$ & & $\begin{array}{l}\text { Teneurin } \\
\text { Transmembrane } \\
\text { Protein } 4\end{array}$ & & & & Fibrillin 1 & & & & \\
\hline IGLC6 & $\begin{array}{l}\text { Immunoglobulin } \\
\text { Lambda Constant } 7\end{array}$ & TENM4 & $\begin{array}{c}\text { Transmembrane } \\
\text { O-Mannosyltransferase } \\
\text { Targeting Cadherins } 3\end{array}$ & & & FBN1 & $\begin{array}{l}\text { Fibrinogen } \\
\text { Alpha Chain }\end{array}$ & & & & \\
\hline IGLC7 & $\begin{array}{l}\text { Immunoglobulin } \\
\text { Lambda Like } \\
\text { Polypeptide } 1\end{array}$ & TMTC3 & Testis Specific 10 & & & FGA & $\begin{array}{l}\text { Fibrinogen } \\
\text { Beta Chain }\end{array}$ & & & & \\
\hline IGLL1 & $\begin{array}{l}\text { Immunoglobulin } \\
\text { Lambda Like } \\
\text { Polypeptide } 5\end{array}$ & TSGA10 & Transthyretin & & & FGB & $\begin{array}{l}\text { Fibrinogen } \\
\text { Gamma Chain }\end{array}$ & & & & \\
\hline IGLL5 & $\begin{array}{c}\text { Interferon } \\
\text { Regulatory Factor } 7\end{array}$ & TTR & $\begin{array}{l}\text { Ubiquitin Specific } \\
\text { Peptidase } 10\end{array}$ & & & FGG & Fibromodulin & & & & \\
\hline
\end{tabular}


Table 2. Cont.

\begin{tabular}{|c|c|c|c|c|c|c|c|c|c|c|c|}
\hline \multicolumn{12}{|c|}{ Protein Expressed in Each Group of TMJ Synovial Fluid Sample $(n=225)$} \\
\hline \multicolumn{2}{|c|}{ DDWoR $(n=70)$} & \multicolumn{2}{|c|}{ MD $(n=34)$} & \multicolumn{2}{|c|}{$\mathrm{CH}(n=1)$} & \multicolumn{2}{|c|}{ DDWoR and MD $(n=114)$} & \multirow{2}{*}{$\begin{array}{c}\begin{array}{c}\text { DDWoR and } \\
\text { CH }(n=0)\end{array} \\
\mathrm{X}\end{array}$} & \multirow{2}{*}{$\begin{array}{c}\text { MD and CH } \\
(n=0)\end{array}$} & \multicolumn{2}{|c|}{ DDWoR, MD and CH $(n=6)$} \\
\hline Code & Name & Code & Name & Code & Name & Code & Name & & & Code & Name \\
\hline KALRN & $\begin{array}{l}\text { Kelch Repeat And } \\
\text { BTB Domain } \\
\text { Containing } 11\end{array}$ & & & & & FN1 & $\begin{array}{l}\text { Glyceraldehyde- } \\
\text { 3-Phosphate } \\
\text { Dehydroge- } \\
\text { nase }\end{array}$ & & & & \\
\hline KBTBD11 & Keratocan & & & & & GAPDH & Gelsolin & & & & \\
\hline KERA & Keratin 18 & & & & & GSN & $\begin{array}{l}\text { H2B Clustered } \\
\text { Histone } 11\end{array}$ & & & & \\
\hline KRT18 & Keratin 7 & & & & & H2BC11 & $\begin{array}{l}\text { H2B Clustered } \\
\text { Histone } 12\end{array}$ & & & & \\
\hline KRT7 & Keratin 8 & & & & & $\mathrm{H} 2 \mathrm{BC} 12$ & $\begin{array}{l}\text { H2B Clustered } \\
\text { Histone } 13\end{array}$ & & & & \\
\hline KRT8 & Keratin 84 & & & & & H2BC13 & $\begin{array}{l}\text { H2B Clustered } \\
\text { Histone } 14\end{array}$ & & & & \\
\hline KRT84 & $\begin{array}{c}\text { Putative } \\
\text { Uncharacterized } \\
\text { Protein }\end{array}$ & & & & & $\mathrm{H} 2 \mathrm{BC} 14$ & $\begin{array}{l}\text { H2B Clustered } \\
\text { Histone } 15\end{array}$ & & & & \\
\hline LOC400499 & $\begin{array}{c}\text { Leucine Rich } \\
\text { Repeat Containing } 9\end{array}$ & & & & & H2BC15 & $\begin{array}{l}\text { H2B Clustered } \\
\text { Histone } 17\end{array}$ & & & & \\
\hline LRRC9 & $\begin{array}{c}\text { Mitogen-Activated } \\
\text { Protein Kinase } \\
\text { Kinase Kinase } 7\end{array}$ & & & & & $\mathrm{H} 2 \mathrm{BC} 17$ & $\begin{array}{l}\text { H2B Clustered } \\
\text { Histone } 18\end{array}$ & & & & \\
\hline MAP3K7 & $\begin{array}{c}\text { Microfibril } \\
\text { Associated Protein } 5\end{array}$ & & & & & H2BC18 & $\begin{array}{l}\text { H2B Clustered } \\
\text { Histone } 21\end{array}$ & & & & \\
\hline MFAP5 & $\begin{array}{l}\text { Myosin Light } \\
\text { Chain 6B }\end{array}$ & & & & & $\mathrm{H} 2 \mathrm{BC} 21$ & $\begin{array}{l}\text { H2B Clustered } \\
\text { Histone } 3\end{array}$ & & & & \\
\hline MYL6B & $\begin{array}{l}\text { NCK Associated } \\
\text { Protein } 5\end{array}$ & & & & & $\mathrm{H} 2 \mathrm{BC} 3$ & $\begin{array}{l}\text { H2B Clustered } \\
\text { Histone } 5\end{array}$ & & & & \\
\hline NCKAP5 & Nik Related Kinase & & & & & $\mathrm{H} 2 \mathrm{BC} 5$ & $\begin{array}{l}\text { H2B Clustered } \\
\text { Histone } 9\end{array}$ & & & & \\
\hline
\end{tabular}


Table 2. Cont.

Protein Expressed in Each Group of TMJ Synovial Fluid Sample $(n=225)$

\begin{tabular}{|c|c|c|c|c|c|c|c|c|c|c|c|}
\hline \multicolumn{2}{|c|}{ DDWoR $(n=70)$} & \multicolumn{2}{|c|}{$\operatorname{MD}(n=34)$} & \multicolumn{2}{|c|}{$\mathrm{CH}(n=1)$} & \multicolumn{2}{|c|}{ DDWoR and MD $(n=114)$} & \multirow{2}{*}{$\begin{array}{c}\begin{array}{c}\text { DDWoR and } \\
\text { CH }(n=0)\end{array} \\
\mathrm{X}\end{array}$} & \multirow{2}{*}{$\begin{array}{c}\text { MD and CH } \\
(n=0)\end{array}$} & \multicolumn{2}{|c|}{ DDWoR, MD and CH $(n=6$} \\
\hline Code & Name & Code & Name & Code & Name & Code & Name & & & Code & Name \\
\hline NRK & $\begin{array}{l}\text { Pericentriolar } \\
\text { Material } 1\end{array}$ & & & & & H2BC9 & $\begin{array}{c}\text { H2B.S } \\
\text { Histone } 1\end{array}$ & & & & \\
\hline PCM1 & $\begin{array}{c}\text { Procollagen } \\
\text { C-Endopeptidase } \\
\text { Enhancer }\end{array}$ & & & & & H2BS1 & $\begin{array}{l}\text { H2B.U } \\
\text { Histone } 1\end{array}$ & & & & \\
\hline PCOLCE & RAD54 Like & & & & & H2BU1 & $\begin{array}{l}\text { Hemoglobin } \\
\text { Subunit } \\
\text { Alpha } 1\end{array}$ & & & & \\
\hline RAD54L & $\begin{array}{c}\text { Retinol } \\
\text { Dehydrogenase } 5\end{array}$ & & & & & HBA1 & $\begin{array}{c}\text { Hemoglobin } \\
\text { Subunit } \\
\text { Alpha } 2 \\
\end{array}$ & & & & \\
\hline RDH5 & Ret Proto-Oncogene & & & & & HBA2 & $\begin{array}{l}\text { Hemoglobin } \\
\text { Subunit Beta }\end{array}$ & & & & \\
\hline RET & $\begin{array}{l}\text { Regulatory Factor } \\
\text { X1 }\end{array}$ & & & & & HBB & $\begin{array}{l}\text { Hemoglobin } \\
\text { Subunit Delta }\end{array}$ & & & & \\
\hline RFX1 & $\begin{array}{c}\text { RPTOR } \\
\text { Independent } \\
\text { Companion Of } \\
\text { MTOR Complex } 2\end{array}$ & & & & & HBD & $\begin{array}{l}\text { Hemoglobin } \\
\text { Subunit } \\
\text { Epsilon } 1\end{array}$ & & & & \\
\hline RICTOR & $\begin{array}{l}\text { RIMS Binding } \\
\text { Protein } 3\end{array}$ & & & & & HBE1 & $\begin{array}{l}\text { Hemoglobin } \\
\text { Subunit } \\
\text { Gamma } 1\end{array}$ & & & & \\
\hline RIMBP3 & $\begin{array}{l}\text { RUN And FYVE } \\
\text { Domain } \\
\text { Containing } 2\end{array}$ & & & & & HBG1 & $\begin{array}{l}\text { Hemoglobin } \\
\text { Subunit } \\
\text { Gamma } 2\end{array}$ & & & & \\
\hline RUFY2 & $\begin{array}{l}\text { Serpin Family C } \\
\text { Member } 1\end{array}$ & & & & & HBG2 & Haptoglobin & & & & \\
\hline SERPINC1 & $\begin{array}{l}\text { Serpin Family F } \\
\text { Member } 1\end{array}$ & & & & & $\mathrm{HP}$ & $\begin{array}{c}\text { Heat Shock } \\
\text { Protein Family } \\
\text { B (Small) } \\
\text { Member } 1\end{array}$ & & & & \\
\hline
\end{tabular}


Table 2. Cont.

Protein Expressed in Each Group of TMJ Synovial Fluid Sample $(n=225)$

\begin{tabular}{|c|c|c|c|c|c|c|c|c|c|c|c|}
\hline \multicolumn{2}{|c|}{ DDWoR $(n=70)$} & \multicolumn{2}{|c|}{$\operatorname{MD}(n=34)$} & \multicolumn{2}{|c|}{$\mathrm{CH}(n=1)$} & \multicolumn{2}{|c|}{ DDWoR and MD $(n=114)$} & \multirow{2}{*}{$\begin{array}{c}\begin{array}{c}\text { DDWoR and } \\
\text { CH }(n=0)\end{array} \\
\mathrm{X}\end{array}$} & \multirow{2}{*}{$\begin{array}{c}\begin{array}{c}\mathrm{MD} \text { and } \mathrm{CH} \\
(n=0)\end{array} \\
\mathrm{X}\end{array}$} & \multicolumn{2}{|c|}{ DDWoR, MD and CH $(n=6)$} \\
\hline Code & Name & Code & Name & Code & Name & Code & Name & & & Code & Name \\
\hline SERPINF1 & $\begin{array}{l}\text { SEC14 And Spectrin } \\
\text { Domain } \\
\text { Containing } 1\end{array}$ & & & & & HSPB1 & $\begin{array}{c}\text { Immunoglobul } \\
\text { Heavy } \\
\text { Constant } \\
\text { Alpha } 1\end{array}$ & & & & \\
\hline SESTD1 & $\begin{array}{l}\text { Small Nuclear } \\
\text { Ribonucleoprotein } \\
\text { U5 Subunit } 200\end{array}$ & & & & & IGHA1 & $\begin{array}{l}\text { Immunoglobul } \\
\text { Heavy } \\
\text { Constant } \\
\text { Alpha 2 (A2m } \\
\text { Marker) }\end{array}$ & & & & \\
\hline SNRNP200 & SVOP Like & & & & & IGHA2 & $\begin{array}{c}\text { Immunoglobul } \\
\text { Heavy } \\
\text { Constant } \\
\text { Gamma 1 } \\
\text { (G1m Marker }\end{array}$ & & & & \\
\hline SVOPL & $\begin{array}{l}\text { Transcription } \\
\text { Elongation Factor, } \\
\text { Mitochondrial }\end{array}$ & & & & & IGHG1 & $\begin{array}{c}\text { Immunoglobuli } \\
\text { Heavy } \\
\text { Constant } \\
\text { Gamma } 2\end{array}$ & & & & \\
\hline TEFM & Thrombospondin 3 & & & & & IGHG2 & $\begin{array}{c}\text { Immunoglobuli } \\
\text { Heavy } \\
\text { Constant } \\
\text { Gamma } 3\end{array}$ & & & & \\
\hline THBS3 & Tenascin C & & & & & IGHG3 & $\begin{array}{c}\text { Immunoglobuli } \\
\text { Heavy } \\
\text { Constant } \\
\text { Gamma } 4\end{array}$ & & & & \\
\hline TNC & $\begin{array}{l}\text { Trio Rho Guanine } \\
\text { Nucleotide } \\
\text { Exchange Factor }\end{array}$ & & & & & IGHG4 & $\begin{array}{c}\text { Immunoglobuli } \\
\text { Kappa } \\
\text { Constant }\end{array}$ & & & & \\
\hline TRIO & $\begin{array}{l}\text { Tubulin Beta } 1 \\
\text { Class VI }\end{array}$ & & & & & IGKC & $\begin{array}{c}\text { Internexin } \\
\text { Neuronal } \\
\text { Intermediate } \\
\text { Filament } \\
\text { Protein Alpha }\end{array}$ & & & & \\
\hline
\end{tabular}


Table 2. Cont.

Protein Expressed in Each Group of TMJ Synovial Fluid Sample $(n=225)$

Ubiquitin Specific

Peptidase 42

WW Domain

1 Like

Zinc Finger

ZZ-Type And

EF-Hand Domain

Containing 1

ZZEF1 H2B Clustered

Histone 1
DDWoR $(n=70)$

Binding Protein

$\mathrm{CH}(n=1)$

DDWoR and MD $(n=114)$

INA Galectin 1

LGALS1 Lamin

LMNA Lumican

Microfibril

Associated

Protein 4

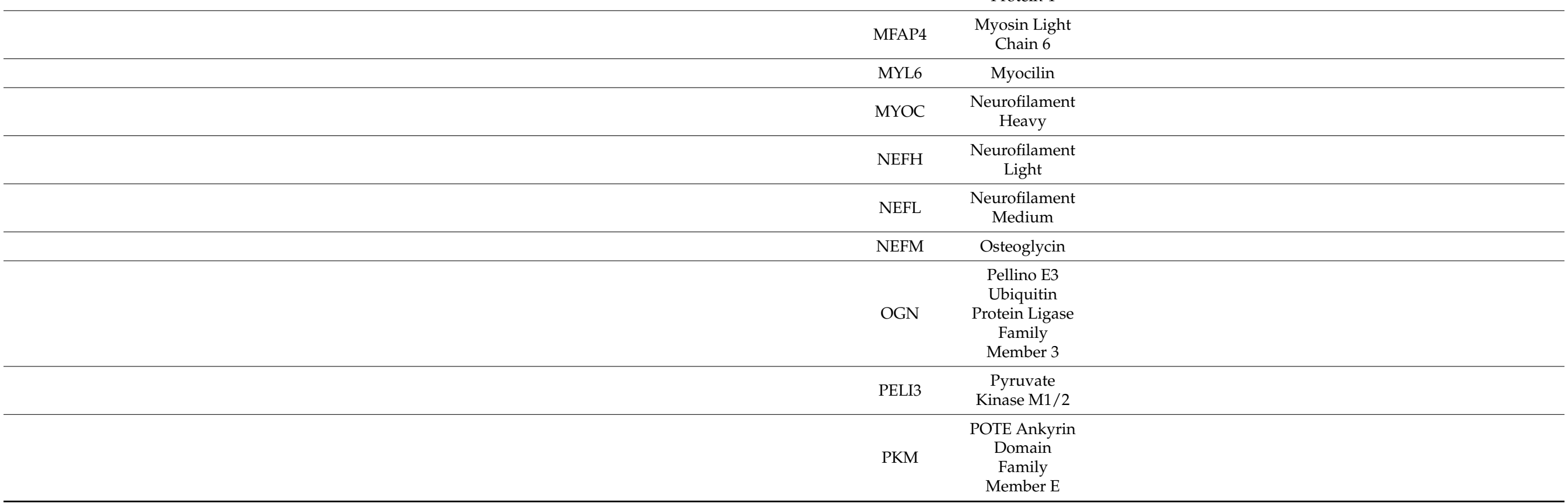

DDWoR and
CH $(n=0)$$\quad \begin{gathered}\text { MD and CH } \\ (n=0)\end{gathered} \quad$ DDWoR, MD and CH $(n=6)$ 
Table 2. Cont.

Protein Expressed in Each Group of TMJ Synovial Fluid Sample $(n=225)$

$\operatorname{DDWoR}(n=70)$

$\operatorname{MD}(n=34)$

$\mathrm{CH}(n=1)$

DDWoR and MD $(n=114)$

DDWoR and

$\mathrm{MD}$ and $\mathrm{CH}$

$\mathrm{CH}(n=0)$

$(n=0)$

DDWoR, MD and CH $(n=6)$

POTE Ankyrin

Domain

Family

POTE Ankyrin

Domain

Family

Family

POTE Ankyrin

Domain

Family

Fember J

POTE Ankyrin

Domain

Family

Member K,

Member K,
Pseudogene

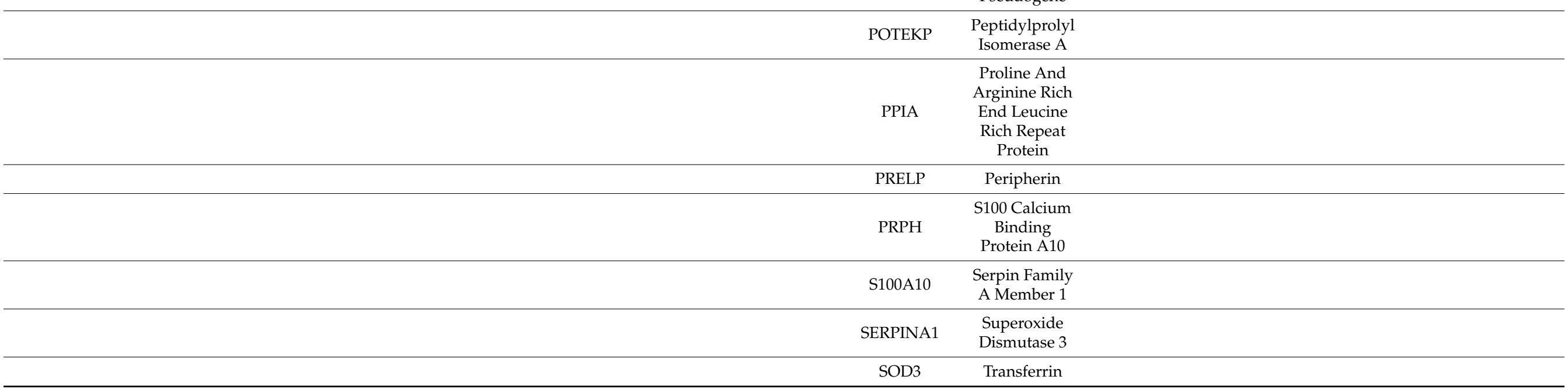


Table 2. Cont.

Protein Expressed in Each Group of TMJ Synovial Fluid Sample $(n=225)$

DDWoR $(n=70)$

MD $(n=34)$

$\mathrm{CH}(n=1)$

DDWoR and MD $(n=114)$

DDWoR and

$\mathrm{MD}$ and $\mathrm{CH}$

$\mathrm{CH}(n=0)$

$(n=0)$

DDWoR, MD and CH $(n=6)$

TF Transforming

Growth Factor

Beta Induced

TGFBI Thrombospondin 4

THBS4 Tenascin XA

TNXA Tenascin XB

TNXB Tubulin

Tubulin

Alpha 1b

TUBA1B Tubulin

TUBA1C Tubulin

Alpha 3c

TUBA3C Tubulin

TUBA3D Tubulin

Alpha 3e

TUBA3E Tubulin

TUBA4A Tubulin

Alpha 8

TUBA8 Tubulin Beta

TUBB Tubulin Bet

2A Class IIa

TUBB2A Tubulin Beta

Tubulin Beta 3

Class III

TUBB3 Tubulin Beta 
Table 2. Cont.

Protein Expressed in Each Group of TMJ Synovial Fluid Sample $(n=225)$

\begin{tabular}{|c|c|c|c|c|c|c|c|}
\hline \multirow[t]{2}{*}{ DDWoR $(n=70)$} & \multirow[t]{2}{*}{ MD $(n=34)$} & \multirow[t]{2}{*}{$\mathrm{CH}(n=1)$} & \multicolumn{2}{|c|}{ DDWoR and MD $(n=114)$} & \multirow[t]{2}{*}{$\begin{array}{l}\text { DDWoR and } \\
\text { CH }(n=0)\end{array}$} & \multirow[t]{2}{*}{$\begin{array}{l}\text { MD and CH } \\
(n=0)\end{array}$} & \multirow[t]{2}{*}{ DDWoR, MD and CH $(n=6$} \\
\hline & & & TUBB4A & $\begin{array}{l}\text { Tubulin Beta } \\
\text { 4B Class IVb }\end{array}$ & & & \\
\hline & & & TUBB4B & $\begin{array}{c}\text { Tubulin Beta } 6 \\
\text { Class V }\end{array}$ & & & \\
\hline & & & TUBB6 & $\begin{array}{c}\text { Tubulin Beta } 8 \\
\text { Class VIII }\end{array}$ & & & \\
\hline & & & TUBB8 & $\begin{array}{l}\text { Tubulin } \\
\text { Beta 8B }\end{array}$ & & & \\
\hline & & & TUBB8B & Versican & & & \\
\hline & & & VCAN & VIM & & & \\
\hline & & & VIM & $\begin{array}{l}\text { ABI Family } \\
\text { Member } 3 \\
\text { Binding } \\
\text { Protein }\end{array}$ & & & \\
\hline
\end{tabular}

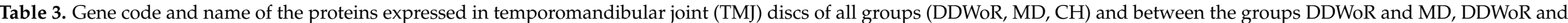
$\mathrm{CH}, \mathrm{MD}$ and $\mathrm{CH}$ and DDWoR, MD and $\mathrm{CH}$.

\begin{tabular}{|c|c|c|c|c|c|c|c|c|c|c|c|c|c|}
\hline \multicolumn{14}{|c|}{ Protein Expressed in Each Group of TMJ Disc Sample $(n=379)$} \\
\hline \multicolumn{2}{|r|}{$\begin{array}{c}\text { DDWoR } \\
(n=66)\end{array}$} & \multicolumn{2}{|c|}{$\operatorname{MD}(n=38)$} & \multicolumn{2}{|c|}{$\mathrm{CH}(n=89)$} & \multicolumn{2}{|c|}{ DDWoR and MD $(n=9)$} & \multicolumn{2}{|c|}{ DDWoR and CH $(n=28)$} & \multicolumn{2}{|c|}{$\mathrm{MD}$ and $\mathrm{CH}(n=17)$} & \multicolumn{2}{|c|}{$\begin{array}{c}\text { DDWoR, MD and CH } \\
(n=132)\end{array}$} \\
\hline Code & Name & Code & Name & Code & Name & Code & Name & Code & Name & Code & Name & Code & Name \\
\hline АВСС 9 & $\begin{array}{l}\text { ATP Binding Cassette } \\
\text { Subfamily C } \\
\text { Member } 9\end{array}$ & AFTPH & Aftiphilin & ACTN1 & Actinin Alpha 1 & АТР7B & $\begin{array}{l}\text { ATPase Copper } \\
\text { Transporting } \\
\text { Beta }\end{array}$ & ACAN & Aggrecan & ATP5F1B & $\begin{array}{l}\text { ATP Synthase } \\
\text { F1 Subunit } \\
\text { Beta }\end{array}$ & $\mathrm{A} 2 \mathrm{M}$ & $\begin{array}{l}\text { Alpha-2- } \\
\text { Macroglobulin }\end{array}$ \\
\hline ACSS3 & $\begin{array}{c}\text { Acyl-CoA Synthetase } \\
\text { Short Chain Family } \\
\text { Member } 3\end{array}$ & AKAP13 & $\begin{array}{l}\text { A-kinase anchor } \\
\text { protein } 13\end{array}$ & ACTN4 & Actinin Alpha 4 & AXIN2 & Axin 2 & $\mathrm{APOH}$ & $\begin{array}{l}\text { Apolipoprotein } \\
\mathrm{H}\end{array}$ & GFAP & $\begin{array}{c}\text { Glial } \\
\text { Fibrillary } \\
\text { Acidic } \\
\text { Protein }\end{array}$ & АВІЗВР & $\begin{array}{l}\text { ABI Family } \\
\text { Member } 3 \\
\text { Binding Protein }\end{array}$ \\
\hline AGO4 & $\begin{array}{l}\text { Argonaute RISC } \\
\text { Component } 4\end{array}$ & ALDH3A2 & $\begin{array}{c}\text { Aldehyde } \\
\text { dehydrogenase } \\
\text { family } 3 \\
\text { member A2 }\end{array}$ & ACTR3 & $\begin{array}{l}\text { Actin Related } \\
\text { Protein } 3\end{array}$ & $\mathrm{C} 4 \mathrm{~A}$ & $\begin{array}{c}\text { Complement } \\
\text { C4A }\end{array}$ & BRD3 & $\begin{array}{l}\text { Bromodomain } \\
\text { Containing } 3\end{array}$ & KRT3 & Keratin 3 & ACTA1 & $\begin{array}{l}\text { Actin Alpha 1, } \\
\text { Skeletal Muscle }\end{array}$ \\
\hline
\end{tabular}


Table 3. Cont

\begin{tabular}{|c|c|c|c|c|c|c|c|c|c|c|c|c|c|}
\hline \multicolumn{14}{|c|}{ Protein Expressed in Each Group of TMJ Disc Sample $(n=379)$} \\
\hline \multicolumn{2}{|r|}{$\begin{array}{c}\text { DDWoR } \\
(n=66)\end{array}$} & \multicolumn{2}{|c|}{$\mathrm{MD}(n=38)$} & \multicolumn{2}{|c|}{$\mathrm{CH}(n=89)$} & \multicolumn{2}{|c|}{ DDWoR and MD $(n=9)$} & \multicolumn{2}{|c|}{ DDWoR and CH $(n=28)$} & \multicolumn{2}{|c|}{$\mathrm{MD}$ and $\mathrm{CH}(n=17)$} & \multicolumn{2}{|c|}{$\begin{array}{c}\text { DDWoR, MD and CH } \\
(n=132)\end{array}$} \\
\hline Code & Name & Code & Name & Code & Name & Code & Name & Code & Name & Code & Name & Code & Name \\
\hline AMBP & $\begin{array}{l}\text { Alpha-1- } \\
\text { Microglobulin/Bikunin } \\
\text { Precursor }\end{array}$ & ANKRD44 & $\begin{array}{l}\text { Serine/threonine- } \\
\text { protein } \\
\text { phosphatase } 6 \\
\text { regulatory } \\
\text { ankyrin repeat } \\
\text { subunit B }\end{array}$ & ADAM10 & $\begin{array}{l}\text { ADAM Metal- } \\
\text { lopeptidase } \\
\text { Domain } 10\end{array}$ & $\mathrm{C} 4 \mathrm{~B}$ & $\begin{array}{l}\text { Complement } \\
\text { C4B }\end{array}$ & CLTC & $\begin{array}{l}\text { Clathrin Heavy } \\
\text { Chain }\end{array}$ & KRT5 & Keratin 5 & ACTA2 & $\begin{array}{l}\text { Actin Alpha 2, } \\
\text { Smooth Muscle }\end{array}$ \\
\hline ANKRD17 & $\begin{array}{l}\text { Ankyrin Repeat } \\
\text { Domain } 17\end{array}$ & ANKRD52 & $\begin{array}{l}\text { Serine/threonine- } \\
\text { protein } \\
\text { phosphatase } 6 \\
\text { regulatory } \\
\text { ankyrin repeat } \\
\text { subunit C } \\
\end{array}$ & ADSL & $\begin{array}{l}\text { Adenylosuccinate } \\
\text { Lyase }\end{array}$ & C4B_2 & $\begin{array}{c}\text { Complement } \\
\text { Component } 4 \mathrm{~B}\end{array}$ & COL1A1 & $\begin{array}{l}\text { Collagen Type I } \\
\text { Alpha } 1 \text { Chain }\end{array}$ & KRT6A & Keratin 6A & АСТВ & Actin Beta \\
\hline ARHGAP35 & $\begin{array}{c}\text { Rho GTPase } \\
\text { Activating Protein } 35\end{array}$ & ARMH3 & $\begin{array}{l}\text { Armadillo-like } \\
\text { helical domain- } \\
\text { containing } \\
\text { protein } 3\end{array}$ & ALDOA & $\begin{array}{c}\text { Aldolase, } \\
\text { Fructose- } \\
\text { Bisphosphate } \\
\text { A }\end{array}$ & KERA & Keratocan & COL4A6 & $\begin{array}{l}\text { Collagen Type } \\
\text { IV Alpha } 6 \\
\text { Chain }\end{array}$ & KRT6B & Keratin 6B & ACTBL2 & Actin Beta Like 2 \\
\hline ARHGEF10 & $\begin{array}{c}\text { Rho Guanine } \\
\text { Nucleotide Exchange } \\
\text { Factor } 10\end{array}$ & CCDC88A & Girdin & ALDOC & $\begin{array}{c}\text { Aldolase, } \\
\text { Fructose- } \\
\text { Bisphosphate } \\
\text { C }\end{array}$ & KIAA0556 & $\begin{array}{l}\text { Katanin } \\
\text { Interacting } \\
\text { Protein }\end{array}$ & DNAH8 & $\begin{array}{l}\text { Defensin } \\
\text { Alpha } 1\end{array}$ & KRT6C & Keratin 6C & ACTC1 & $\begin{array}{c}\text { Actin Alpha } \\
\text { Cardiac Muscle } 1\end{array}$ \\
\hline ATAD2B & $\begin{array}{l}\text { ATPase Family AAA } \\
\text { Domain } \\
\text { Containing 2B }\end{array}$ & CLUH & $\begin{array}{l}\text { Clustered } \\
\text { mitochondria } \\
\text { protein } \\
\text { homolog } \\
\end{array}$ & ANKMY1 & $\begin{array}{c}\text { Ankyrin Repeat } \\
\text { And MYND } \\
\text { Domain } \\
\text { Containing } 1 \\
\end{array}$ & MAP4 & $\begin{array}{l}\text { Microtubule } \\
\text { Associated } \\
\text { Protein } 4\end{array}$ & EEF1A1 & $\begin{array}{c}\text { Dynein } \\
\text { Axonemal } \\
\text { Heavy Chain } 8\end{array}$ & KRT75 & Keratin 75 & ACTG1 & Actin Gamma 1 \\
\hline BCAS2 & $\begin{array}{l}\text { BCAS2 Pre-MRNA } \\
\text { Processing Factor }\end{array}$ & COL4A1 & $\begin{array}{l}\text { Collagen } \\
\text { alpha-1(IV) } \\
\text { chain }\end{array}$ & ANXA5 & Annexin A5 & SEMA4F & Semaphorin $4 \mathrm{~F}$ & EEF1A1P5 & $\begin{array}{c}\text { Eukaryotic } \\
\text { Translation } \\
\text { Elongation } \\
\text { Factor 1 } \\
\text { Alpha 1 }\end{array}$ & KRT76 & Keratin 76 & ACTG2 & Actin Gamma 2 \\
\hline CARNS1 & Carnosine Synthase 1 & DOCK10 & $\begin{array}{l}\text { Dedicator of } \\
\text { cytokinesis } \\
\text { protein } 10\end{array}$ & ANXA6 & Annexin A6 & & & EEF1A2 & $\begin{array}{c}\text { Eukaryotic } \\
\text { Translation } \\
\text { Elongation } \\
\text { Factor 1 Alpha } 1 \\
\text { Pseudogene 5 }\end{array}$ & KRT78 & Keratin 78 & ALB & Albumin \\
\hline CCDC187 & $\begin{array}{l}\text { Coiled-Coil Domain } \\
\text { Containing } 187\end{array}$ & DTHD1 & $\begin{array}{l}\text { Death domain- } \\
\text { containing } \\
\text { protein } 1\end{array}$ & ASXL1 & $\begin{array}{c}\text { ASXL } \\
\text { Transcriptional } \\
\text { Regulator } 1\end{array}$ & & & HMCN2 & $\begin{array}{c}\text { Eukaryotic } \\
\text { Translation } \\
\text { Elongation } \\
\text { Factor 1 } \\
\text { Alpha } 2\end{array}$ & KRT79 & Keratin 79 & ANXA1 & Annexin A1 \\
\hline
\end{tabular}


Table 3. Cont

\begin{tabular}{|c|c|c|c|c|c|c|c|c|c|c|c|c|c|}
\hline \multicolumn{14}{|c|}{ Protein Expressed in Each Group of TMJ Disc Sample $(n=379)$} \\
\hline \multicolumn{2}{|r|}{$\begin{array}{l}\text { DDWoR } \\
(n=66)\end{array}$} & \multicolumn{2}{|c|}{$\mathrm{MD}(n=38)$} & \multicolumn{2}{|c|}{$\mathrm{CH}(n=89)$} & \multicolumn{2}{|c|}{ DDWoR and MD $(n=9)$} & \multicolumn{2}{|c|}{ DDWoR and $\mathrm{CH}(n=28)$} & \multicolumn{2}{|c|}{$\mathrm{MD}$ and $\mathrm{CH}(n=17)$} & \multicolumn{2}{|c|}{$\begin{array}{c}\text { DDWoR, MD and CH } \\
\quad(n=132)\end{array}$} \\
\hline Code & Name & Code & Name & Code & Name & Code & Name & Code & Name & Code & Name & Code & Name \\
\hline CDCP1 & $\begin{array}{c}\text { CUB Domain } \\
\text { Containing Protein } 1\end{array}$ & ERAS & GTPase ERas & ATP2C1 & $\begin{array}{c}\text { ATPase } \\
\text { Secretory } \\
\text { Pathway Ca2+ } \\
\text { Transporting 1 }\end{array}$ & & & HSPA2 & Hemicentin 2 & KRT81 & Keratin 81 & ANXA2 & Annexin A2 \\
\hline $\mathrm{CDH} 3$ & Cadherin 3 & ERBIN & Erbin & BLOC1S1 & $\begin{array}{c}\text { Biogenesis Of } \\
\text { Lysosomal } \\
\text { Organelles } \\
\text { Complex 1 } \\
\text { Subunit 1 }\end{array}$ & & & HSPA8 & $\begin{array}{c}\text { Heat Shock } \\
\text { Protein Family } \\
\text { A (Hsp70) } \\
\text { Member } 2\end{array}$ & KRT83 & Keratin 83 & ANXA2P2 & $\begin{array}{l}\text { Annexin A2 } \\
\text { Pseudogene } 2\end{array}$ \\
\hline CHD7 & $\begin{array}{l}\text { Chromodomain } \\
\text { Helicase DNA } \\
\text { Binding Protein } 7\end{array}$ & FLNA & Filamin-A & BRCA2 & $\begin{array}{l}\text { BRCA2 DNA } \\
\text { Repair } \\
\text { Associated }\end{array}$ & & & HYDIN & $\begin{array}{l}\text { Heat Shock } \\
\text { Protein Family } \\
\text { A (Hsp70) } \\
\text { Member 8 }\end{array}$ & KRT85 & Keratin 85 & APCS & $\begin{array}{l}\text { Amyloid P } \\
\text { Component }\end{array}$ \\
\hline CHD8 & $\begin{array}{l}\text { Chromodomain } \\
\text { Helicase DNA } \\
\text { Binding Protein } 8\end{array}$ & GOT1L1 & $\begin{array}{c}\text { Putative } \\
\text { aspartate } \\
\text { aminotrans- } \\
\text { ferase, } \\
\text { cytoplasmic 2 }\end{array}$ & CABP5 & $\begin{array}{l}\text { Calcium } \\
\text { Binding } \\
\text { Protein } 5\end{array}$ & & & IGLC1 & $\begin{array}{l}\text { HYDIN } \\
\text { Axonemal } \\
\text { Central Pair } \\
\text { Apparatus } \\
\text { Protein }\end{array}$ & KRT86 & Keratin 86 & APOA1 & $\begin{array}{l}\text { Apolipoprotein } \\
\text { A1 }\end{array}$ \\
\hline CHD9 & $\begin{array}{l}\text { Chromodomain } \\
\text { Helicase DNA } \\
\text { Binding Protein } 9\end{array}$ & HHLA1 & $\begin{array}{l}\text { HERV-H } \\
\text { LTR-associating } \\
\text { protein } 1\end{array}$ & CACNA2D3 & $\begin{array}{c}\text { Calcium } \\
\text { Voltage-Gated } \\
\text { Channel } \\
\text { Auxiliary } \\
\text { Subunit } \\
\text { Alpha2delta 3 }\end{array}$ & & & IGLC2 & $\begin{array}{l}\text { Immunoglobulin } \\
\text { Lambda } \\
\text { Constant } 1\end{array}$ & PKM & $\begin{array}{c}\text { Pyruvate } \\
\text { Kinase M1/2 }\end{array}$ & ASPN & Asporin \\
\hline CSTF2T & $\begin{array}{c}\text { Cleavage Stimulation } \\
\text { Factor Subunit } 2 \text { Tau } \\
\text { Variant }\end{array}$ & $\begin{array}{l}\text { IGHV3OR16- } \\
9\end{array}$ & $\begin{array}{l}\text { Immunoglobulin } \\
\text { heavy variable } \\
\text { 3/OR16-9 } \\
\text { (non-functional) }\end{array}$ & CCDC18 & $\begin{array}{l}\text { Coiled-Coil } \\
\text { Domain } \\
\text { Containing } 18\end{array}$ & & & IGLC3 & $\begin{array}{l}\text { Immunoglobulin } \\
\text { Lambda } \\
\text { Constant } 2\end{array}$ & ТTBК2 & $\begin{array}{l}\text { Tau Tubulin } \\
\text { Kinase } 2\end{array}$ & BGN & Biglycan \\
\hline ECH1 & $\begin{array}{l}\text { Enoyl-CoA } \\
\text { Hydratase } 1\end{array}$ & KDF1 & $\begin{array}{l}\text { Keratinocyte } \\
\text { differentiation } \\
\quad \text { factor } 1\end{array}$ & CDC20 & $\begin{array}{l}\text { Cell Division } \\
\text { Cycle } 20\end{array}$ & & & IGLC6 & $\begin{array}{l}\text { Immunoglobulin } \\
\text { Lambda } \\
\text { Constant } 3\end{array}$ & & & C3 & Complement $\mathrm{C} 3$ \\
\hline ELAVL3 & $\begin{array}{l}\text { ELAV Like RNA } \\
\text { Binding Protein } 3\end{array}$ & L1CAM & $\begin{array}{l}\text { Neural cell } \\
\text { adhesion } \\
\text { molecule L1 }\end{array}$ & CENPF & $\begin{array}{l}\text { Centromere } \\
\text { Protein F }\end{array}$ & & & IGLC7 & $\begin{array}{c}\text { Immunoglobulin } \\
\text { Lambda } \\
\text { Constant } 6\end{array}$ & & & CILP & $\begin{array}{l}\text { Cartilage } \\
\text { Intermediate } \\
\text { Layer Protein }\end{array}$ \\
\hline EML4 & EMAP Like 4 & MARK1 & $\begin{array}{l}\text { Serine/threonine- } \\
\text { protein kinase } \\
\text { MARK1 }\end{array}$ & CFAP20DC & $\begin{array}{c}\text { CFAP20 } \\
\text { Domain } \\
\text { Containing }\end{array}$ & & & IGLL1 & $\begin{array}{l}\text { Immunoglobulin } \\
\text { Lambda } \\
\text { Constant } 7\end{array}$ & & & CILP2 & $\begin{array}{c}\text { Cartilage } \\
\text { Intermediate } \\
\text { Layer Protein } 2 \\
\end{array}$ \\
\hline FARP2 & $\begin{array}{c}\text { FERM, } \\
\text { ARH/RhoGEF And } \\
\text { Pleckstrin Domain } \\
\text { Protein 2 }\end{array}$ & NEIL3 & $\begin{array}{l}\text { Endonuclease } \\
\quad 8 \text {-like } 3\end{array}$ & CNTN1 & Contactin 1 & & & IGLL5 & $\begin{array}{l}\text { Immunoglobulin } \\
\text { Lambda Like } \\
\text { Polypeptide } 1\end{array}$ & & & CLU & Clusterin \\
\hline
\end{tabular}


Table 3. Cont

\begin{tabular}{|c|c|c|c|c|c|c|c|c|c|c|c|c|c|}
\hline \multicolumn{14}{|c|}{ Protein Expressed in Each Group of TMJ Disc Sample $(n=379)$} \\
\hline \multicolumn{2}{|r|}{$\begin{array}{c}\text { DDWoR } \\
(n=66)\end{array}$} & \multicolumn{2}{|c|}{$\mathrm{MD}(n=38)$} & \multicolumn{2}{|c|}{ CH $(n=89)$} & \multicolumn{2}{|c|}{ DDWoR and MD $(n=9)$} & \multicolumn{2}{|c|}{ DDWoR and $\mathrm{CH}(n=28)$} & \multicolumn{2}{|c|}{$\mathrm{MD}$ and $\mathrm{CH}(n=17)$} & \multicolumn{2}{|c|}{$\begin{array}{c}\text { DDWoR, MD and CH } \\
(n=132)\end{array}$} \\
\hline Code & Name & Code & Name & Code & Name & Code & Name & Code & Name & Code & Name & Code & Name \\
\hline FBN1 & Fibrillin 1 & NOL8 & $\begin{array}{l}\text { Nucleolar } \\
\text { protein } 8\end{array}$ & COQ8B & Coenzyme Q8B & & & LOC441081 & $\begin{array}{l}\text { Immunoglobulin } \\
\text { Lambda Like } \\
\text { Polypeptide } 5\end{array}$ & & & COL12A1 & $\begin{array}{l}\text { Collagen Type } \\
\text { XII Alpha 1 } \\
\text { Chain }\end{array}$ \\
\hline GALK2 & Galactokinase 2 & NUFIP1 & $\begin{array}{l}\text { Nuclear fragile } \\
\text { X mental } \\
\text { retardation- } \\
\text { interacting } \\
\text { protein } 1\end{array}$ & CTNNA3 & Catenin Alpha 3 & & & MIS18BP1 & $\begin{array}{c}\text { POM121 } \\
\text { Membrane } \\
\text { Glycoprotein } \\
\text { (Rat) } \\
\text { Pseudogene }\end{array}$ & & & COL14A1 & $\begin{array}{l}\text { Collagen Type } \\
\text { XIV Alpha } 1 \\
\text { Chain }\end{array}$ \\
\hline GPR162 & $\begin{array}{l}\text { G Protein-Coupled } \\
\text { Receptor } 162\end{array}$ & NUMA1 & $\begin{array}{l}\text { Nuclear mitotic } \\
\text { apparatus } \\
\text { protein } 1\end{array}$ & DPYSL2 & $\begin{array}{l}\text { Dihydropyrimidinase } \\
\text { Like } 2\end{array}$ & & & MYO15B & $\begin{array}{l}\text { MIS18 Binding } \\
\text { Protein } 1\end{array}$ & & & COL6A1 & $\begin{array}{l}\text { Collagen Type VI } \\
\text { Alpha } 1 \text { Chain }\end{array}$ \\
\hline GPRASP1 & $\begin{array}{l}\text { G Protein-Coupled } \\
\text { Receptor Associated } \\
\text { Sorting Protein } 1\end{array}$ & PARP10 & $\begin{array}{l}\text { Protein } \\
\text { mono-ADP- } \\
\text { ribosyltransferase } \\
\text { PARP10 }\end{array}$ & EHD2 & $\begin{array}{l}\text { EH Domain } \\
\text { Containing } 2\end{array}$ & & & POSTN & Myosin XVB & & & COL6A2 & $\begin{array}{c}\text { Collagen Type VI } \\
\text { Alpha } 2 \text { Chain }\end{array}$ \\
\hline IKBKE & $\begin{array}{l}\text { Inhibitor Of Nuclear } \\
\text { Factor Kappa B } \\
\text { Kinase Subunit } \\
\text { Epsilon }\end{array}$ & PCDHA4 & $\begin{array}{l}\text { Protocadherin } \\
\quad \text { alpha-4 }\end{array}$ & EYS & $\begin{array}{l}\text { Eyes Shut } \\
\text { Homolog }\end{array}$ & & & SERPINA9 & Periostin & & & COL6A3 & $\begin{array}{c}\text { Collagen Type VI } \\
\text { Alpha } 3 \text { Chain }\end{array}$ \\
\hline IRF2BPL & $\begin{array}{l}\text { Interferon Regulatory } \\
\text { Factor } 2 \text { Binding } \\
\text { Protein Like }\end{array}$ & POM121L2 & $\begin{array}{l}\text { POM121-like } \\
\text { protein } 2\end{array}$ & GOLGA4 & Golgin A4 & & & & & & & $\mathrm{DCN}$ & Decorin \\
\hline ITGA6 & $\begin{array}{l}\text { Integrin Subunit } \\
\quad \text { Alpha } 6\end{array}$ & PPFIA1 & Liprin-alpha-1 & GSTP1 & $\begin{array}{l}\text { Glutathione } \\
\text { S-Transferase } \\
\quad \text { Pi } 1\end{array}$ & & & & & & & DES & Desmin \\
\hline KRT26 & Keratin 26 & PPFIA2 & Liprin-alpha-2 & GVINP1 & $\begin{array}{l}\text { GTPase, Very } \\
\text { Large Interferon } \\
\text { Inducible } \\
\text { Pseudogene } 1\end{array}$ & & & & & & & DMD & Dystrophin \\
\hline LEMD2 & $\begin{array}{l}\text { LEM Domain Nuclear } \\
\text { Envelope Protein } 2\end{array}$ & PRR14L & Protein PRR14L & $\mathrm{H} 3-2$ & $\begin{array}{l}\text { H3.2 Histone } \\
\text { (Putative) }\end{array}$ & & & & & & & DPT & Dermatopontin \\
\hline МАР3К21 & $\begin{array}{c}\text { Mitogen-Activated } \\
\text { Protein Kinase Kinase } \\
\text { Kinase } 21\end{array}$ & PTPN7 & $\begin{array}{l}\text { Tyrosine- } \\
\text { protein } \\
\text { phosphatase } \\
\text { non-receptor } \\
\text { type } 7\end{array}$ & H3-3A & H3.3 Histone A & & & & & & & ENO1 & Enolase 1 \\
\hline
\end{tabular}


Table 3. Cont

\begin{tabular}{|c|c|c|c|c|c|c|c|c|c|c|c|c|c|}
\hline \multicolumn{14}{|c|}{ Protein Expressed in Each Group of TMJ Disc Sample $(n=379)$} \\
\hline \multicolumn{2}{|r|}{$\begin{array}{c}\text { DDWoR } \\
(n=66)\end{array}$} & \multicolumn{2}{|c|}{$\mathrm{MD}(n=38)$} & \multicolumn{2}{|c|}{$\mathrm{CH}(n=89)$} & \multicolumn{2}{|c|}{ DDWoR and MD $(n=9)$} & \multicolumn{2}{|c|}{ DDWoR and $\mathrm{CH}(n=28)$} & \multicolumn{2}{|c|}{$\mathrm{MD}$ and $\mathrm{CH}(n=17)$} & \multicolumn{2}{|c|}{$\begin{array}{c}\text { DDWoR, MD and CH } \\
(n=132)\end{array}$} \\
\hline Code & Name & Code & Name & Code & Name & Code & Name & Code & Name & Code & Name & Code & Name \\
\hline MDGA1 & $\begin{array}{l}\text { MAM Domain } \\
\text { Containing } \\
\text { Glycosylphos- } \\
\text { phatidylinositol } \\
\text { Anchor 1 } \\
\end{array}$ & RASSF10 & $\begin{array}{c}\text { Ras association } \\
\text { domain- } \\
\text { containing } \\
\text { protein } 10\end{array}$ & H3-3B & H3.3 Histone B & & & & & & & ENO2 & Enolase 2 \\
\hline MMP10 & $\begin{array}{l}\text { Matrix } \\
\text { Metallopeptidase } 10\end{array}$ & RPS6KA6 & $\begin{array}{c}\text { Ribosomal } \\
\text { protein S6 } \\
\text { kinase alpha-6 } \\
\end{array}$ & $\mathrm{H} 3-4$ & H3.4 Histone & & & & & & & ENO3 & Enolase 3 \\
\hline MMP27 & $\begin{array}{c}\text { Matrix } \\
\text { Metallopeptidase } 27\end{array}$ & TRIO & $\begin{array}{c}\text { TRIO and } \\
\text { F-actin-binding } \\
\text { protein }\end{array}$ & $\mathrm{H} 3-5$ & H3.5 Histone & & & & & & & FBLN1 & Fibulin 1 \\
\hline MMP3 & $\begin{array}{c}\text { Matrix } \\
\text { Metallopeptidase } 3 \\
\end{array}$ & TSC1 & Hamartin & HEATR6 & $\begin{array}{l}\text { HEAT Repeat } \\
\text { Containing } 6\end{array}$ & & & & & & & FGA & $\begin{array}{l}\text { Fibrinogen } \\
\text { Alpha Chain }\end{array}$ \\
\hline MOS & $\begin{array}{c}\text { MOS } \\
\text { Proto-Oncogene, } \\
\text { Serine/Threonine } \\
\text { Kinas } \\
\end{array}$ & UPK3A & Uroplakin-3a & HPX & Hemopexin & & & & & & & FGB & $\begin{array}{l}\text { Fibrinogen Beta } \\
\text { Chain }\end{array}$ \\
\hline MYL6 & Myosin Light Chain 6 & UROD & $\begin{array}{l}\text { Uroporphyrinogen } \\
\text { decarboxylase }\end{array}$ & HSP90B1 & $\begin{array}{l}\text { Heat Shock } \\
\text { Protein 90 Beta } \\
\text { Family } \\
\text { Member } 1\end{array}$ & & & & & & & FGG & $\begin{array}{l}\text { Fibrinogen } \\
\text { Gamma Chain }\end{array}$ \\
\hline MYO7B & Myosin VIIB & & & HSPA1A & $\begin{array}{c}\text { Heat Shock } \\
\text { Protein Family } \\
\text { A (Hsp70) } \\
\text { Member 1A }\end{array}$ & & & & & & & FLNB & Filamin B \\
\hline NT5E & 5'-Nucleotidase Ecto & & & HSPA1B & $\begin{array}{c}\text { Heat Shock } \\
\text { Protein Family } \\
\text { A (Hsp70) } \\
\text { Member 1B } \\
\end{array}$ & & & & & & & FMOD & Fibromodulin \\
\hline OLFML1 & Olfactomedin Like 1 & & & HSPA1L & $\begin{array}{c}\text { Heat Shock } \\
\text { Protein Family } \\
\text { A (Hsp70) } \\
\text { Member 1 Like } \\
\end{array}$ & & & & & & & FN1 & Fibronectin 1 \\
\hline PGM5 & $\begin{array}{l}\text { Phosphoglucomutase } \\
5\end{array}$ & & & HSPA5 & $\begin{array}{l}\text { Heat Shock } \\
\text { Protein Family } \\
\text { A (Hsp70) } \\
\text { Member } 5\end{array}$ & & & & & & & GAPDH & $\begin{array}{l}\text { Glyceraldehyde } \\
\text { 3-Phosphate } \\
\text { Dehydrogenase }\end{array}$ \\
\hline
\end{tabular}


Table 3. Cont

\begin{tabular}{|c|c|c|c|c|c|c|c|c|c|c|c|c|c|}
\hline \multicolumn{14}{|c|}{ Protein Expressed in Each Group of TMJ Disc Sample $(n=379)$} \\
\hline \multicolumn{2}{|r|}{$\begin{array}{c}\text { DDWoR } \\
(n=66)\end{array}$} & \multicolumn{2}{|c|}{$\operatorname{MD}(n=38)$} & \multicolumn{2}{|c|}{$\mathrm{CH}(n=89)$} & \multicolumn{2}{|c|}{ DDWoR and MD $(n=9)$} & \multicolumn{2}{|c|}{ DDWoR and CH $(n=28)$} & \multicolumn{2}{|c|}{$\mathrm{MD}$ and $\mathrm{CH}(n=17)$} & \multicolumn{2}{|c|}{$\begin{array}{l}\text { DDWoR, MD and CH } \\
(n=132)\end{array}$} \\
\hline Code & Name & Code & Name & Code & Name & Code & Name & Code & Name & Code & Name & Code & Name \\
\hline PHKA2 & $\begin{array}{c}\text { Phosphorylase Kinase } \\
\text { Regulatory Subunit } \\
\text { Alpha } 2\end{array}$ & & & IGFN1 & $\begin{array}{l}\text { Immunoglobulin } \\
\text { Like And } \\
\text { Fibronectin } \\
\text { Type III Domain } \\
\text { Containing } 1 \\
\end{array}$ & & & & & & & GPX3 & $\begin{array}{l}\text { Glutathione } \\
\text { Peroxidase } 3\end{array}$ \\
\hline PLA2G7 & $\begin{array}{l}\text { Phospholipase A2 } \\
\text { Group VII }\end{array}$ & & & INF2 & $\begin{array}{l}\text { Inverted } \\
\text { Formin } 2\end{array}$ & & & & & & & GSN & $\begin{array}{l}\text { Angiotensin I } \\
\text { Converting } \\
\text { Enzyme 2 }\end{array}$ \\
\hline POR & $\begin{array}{l}\text { Cytochrome P450 } \\
\text { Oxidoreductase }\end{array}$ & & & L3MBTL4 & $\begin{array}{l}\text { L3MBTL } \\
\text { Histone } \\
\text { Methyl-Lysine } \\
\text { Binding } \\
\text { Protein 4 }\end{array}$ & & & & & & & $\mathrm{H} 2 \mathrm{BC} 1$ & $\begin{array}{l}\text { H2B Clustered } \\
\text { Histone } 1\end{array}$ \\
\hline RANBP17 & $\begin{array}{l}\text { RAN Binding Protein } \\
17\end{array}$ & & & LMNB1 & Lamin B1 & & & & & & & H2BC11 & $\begin{array}{l}\text { H2B Clustered } \\
\text { Histone } 11\end{array}$ \\
\hline RGS22 & $\begin{array}{c}\text { Regulator Of G } \\
\text { Protein Signaling } 22 \\
\end{array}$ & & & LMNB2 & Lamin B2 & & & & & & & $\mathrm{H} 2 \mathrm{BC} 12$ & $\begin{array}{l}\text { H2B Clustered } \\
\text { Histone } 12\end{array}$ \\
\hline RIF1 & $\begin{array}{l}\text { Replication Timing } \\
\text { Regulatory Factor } 1\end{array}$ & & & MFAP5 & $\begin{array}{l}\text { Microfibril } \\
\text { Associated } \\
\text { Protein } 5 \\
\end{array}$ & & & & & & & $\mathrm{H} 2 \mathrm{BC} 13$ & $\begin{array}{l}\text { H2B Clustered } \\
\text { Histone } 13\end{array}$ \\
\hline RTN4 & Reticulon 4 & & & MRPL50 & $\begin{array}{c}\text { Mitochondrial } \\
\text { Ribosomal } \\
\text { Protein L50 } \\
\end{array}$ & & & & & & & $\mathrm{H} 2 \mathrm{BC} 14$ & $\begin{array}{l}\text { H2B Clustered } \\
\text { Histone } 14\end{array}$ \\
\hline SARS2 & $\begin{array}{c}\text { Seryl-TRNA } \\
\text { Synthetase 2, } \\
\text { Mitochondrial } \\
\end{array}$ & & & MS4A6A & $\begin{array}{c}\text { Membrane } \\
\text { Spanning } \\
\text { 4-Domains A6A }\end{array}$ & & & & & & & H2BC15 & $\begin{array}{l}\text { H2B Clustered } \\
\text { Histone } 15\end{array}$ \\
\hline SEPHS2 & $\begin{array}{l}\text { Selenophosphate } \\
\text { Synthetase } 2\end{array}$ & & & MUC4 & $\begin{array}{l}\text { Mucin 4, Cell } \\
\text { Surface } \\
\text { Associated }\end{array}$ & & & & & & & H2BC17 & $\begin{array}{l}\text { H2B Clustered } \\
\text { Histone } 17\end{array}$ \\
\hline SLFN13 & $\begin{array}{l}\text { Schlafen Family } \\
\text { Member } 13\end{array}$ & & & MYH14 & $\begin{array}{l}\text { Myosin Heavy } \\
\text { Chain } 14\end{array}$ & & & & & & & $\mathrm{H} 2 \mathrm{BC} 18$ & $\begin{array}{l}\text { H2B Clustered } \\
\text { Histone } 18\end{array}$ \\
\hline SLK & STE20 Like Kinase & & & MYL6B & $\begin{array}{l}\text { Myosin Light } \\
\text { Chain 6B }\end{array}$ & & & & & & & $\mathrm{H} 2 \mathrm{BC} 21$ & $\begin{array}{l}\text { H2B Clustered } \\
\text { Histone } 21\end{array}$ \\
\hline SPATA20 & $\begin{array}{l}\text { Spermatogenesis } \\
\text { Associated } 20\end{array}$ & & & NEK10 & $\begin{array}{l}\text { NIMA Related } \\
\text { Kinase } 10\end{array}$ & & & & & & & $\mathrm{H} 2 \mathrm{BC} 3$ & $\begin{array}{l}\text { H2B Clustered } \\
\text { Histone } 3\end{array}$ \\
\hline SPATA5 & $\begin{array}{l}\text { Spermatogenesis } \\
\text { Associated } 5\end{array}$ & & & PAK3 & $\begin{array}{l}\text { P21 (RAC1) } \\
\text { Activated } \\
\text { Kinase } 3\end{array}$ & & & & & & & Н2BC5 & $\begin{array}{l}\text { H2B Clustered } \\
\text { Histone } 5\end{array}$ \\
\hline
\end{tabular}


Table 3. Cont

\begin{tabular}{|c|c|c|c|c|c|c|c|c|c|c|c|c|c|}
\hline \multicolumn{14}{|c|}{ Protein Expressed in Each Group of TMJ Disc Sample $(n=379)$} \\
\hline \multicolumn{2}{|r|}{$\begin{array}{c}\text { DDWoR } \\
(n=66)\end{array}$} & \multicolumn{2}{|c|}{$\operatorname{MD}(n=38)$} & \multicolumn{2}{|c|}{$\mathrm{CH}(n=89)$} & \multicolumn{2}{|c|}{ DDWoR and MD $(n=9)$} & \multicolumn{2}{|c|}{ DDWoR and CH $(n=28)$} & \multicolumn{2}{|c|}{$\mathrm{MD}$ and $\mathrm{CH}(n=17)$} & \multicolumn{2}{|c|}{$\begin{array}{l}\text { DDWoR, MD and CH } \\
\quad(n=132)\end{array}$} \\
\hline Code & Name & Code & Name & Code & Name & Code & Name & Code & Name & Code & Name & Code & Name \\
\hline SPTA1 & $\begin{array}{l}\text { Spectrin Alpha, } \\
\text { Erythrocytic } 1\end{array}$ & & & PAPOLA & $\begin{array}{l}\text { Poly(A) } \\
\text { Polymerase } \\
\text { Alpha }\end{array}$ & & & & & & & $\mathrm{H} 2 \mathrm{BC} 9$ & $\begin{array}{l}\text { H2B Clustered } \\
\text { Histone } 9\end{array}$ \\
\hline SQLE & Squalene Epoxidase & & & PAPOLG & $\begin{array}{l}\text { Poly(A) } \\
\text { Polymerase } \\
\text { Gamma }\end{array}$ & & & & & & & H2BS1 & H2B.S Histone 1 \\
\hline STIL & $\begin{array}{l}\text { STIL Centriolar } \\
\text { Assembly Protein }\end{array}$ & & & PDLIM4 & $\begin{array}{l}\text { PDZ And LIM } \\
\text { Domain } 4\end{array}$ & & & & & & & HBA1 & $\begin{array}{c}\text { Hemoglobin } \\
\text { Subunit Alpha } 1\end{array}$ \\
\hline TACC2 & $\begin{array}{l}\text { Transforming Acidic } \\
\text { Coiled-Coil } \\
\text { Containing Protein } 2\end{array}$ & & & RALBP1 & $\begin{array}{l}\text { RalA Binding } \\
\text { Protein } 1\end{array}$ & & & & & & & HBA2 & $\begin{array}{c}\text { Hemoglobin } \\
\text { Subunit Alpha } 2\end{array}$ \\
\hline TAP1 & $\begin{array}{l}\text { Transporter 1, ATP } \\
\text { Binding Cassette } \\
\text { Subfamily B Member }\end{array}$ & & & RNF213 & $\begin{array}{l}\text { Ring Finger } \\
\text { Protein } 213\end{array}$ & & & & & & & HBB & $\begin{array}{l}\text { Hemoglobin } \\
\text { Subunit Beta }\end{array}$ \\
\hline THADA & $\begin{array}{l}\text { THADA Armadillo } \\
\text { Repeat Containing }\end{array}$ & & & SBF2 & $\begin{array}{l}\text { SET Binding } \\
\text { Factor } 2\end{array}$ & & & & & & & HBD & $\begin{array}{l}\text { Hemoglobin } \\
\text { Subunit Delta }\end{array}$ \\
\hline THBS3 & Thrombospondin 3 & & & SERPINF1 & $\begin{array}{l}\text { Serpin Family F } \\
\text { Member } 1\end{array}$ & & & & & & & HBE1 & $\begin{array}{l}\text { Hemoglobin } \\
\text { Subunit } \\
\text { Epsilon } 1\end{array}$ \\
\hline UQCRC1 & $\begin{array}{l}\text { Ubiquinol- } \\
\text { Cytochrome C } \\
\text { Reductase Core } \\
\text { Protein } 1\end{array}$ & & & SERPINH1 & $\begin{array}{l}\text { Serpin Family } \\
\text { H Member } 1\end{array}$ & & & & & & & HBG1 & $\begin{array}{l}\text { Hemoglobin } \\
\text { Subunit } \\
\text { Gamma } 1\end{array}$ \\
\hline VWA3A & $\begin{array}{l}\text { Von Willebrand } \\
\text { Factor A Domain } \\
\text { Containing 3A }\end{array}$ & & & SLC4A5 & $\begin{array}{l}\text { Solute Carrier } \\
\text { Family } 4 \\
\text { Member } 5 \\
\end{array}$ & & & & & & & HBG2 & $\begin{array}{l}\text { Hemoglobin } \\
\text { Subunit } \\
\text { Gamma } 2\end{array}$ \\
\hline \multirow[t]{3}{*}{ ZNF333 } & $\begin{array}{l}\text { Zinc Finger } \\
\text { Protein } 333\end{array}$ & & & SLIT2 & $\begin{array}{l}\text { Slit Guidance } \\
\text { Ligand } 2\end{array}$ & & & & & & & HBZ & $\begin{array}{l}\text { Hemoglobin } \\
\text { Subunit Zeta }\end{array}$ \\
\hline & & & & SMPD3 & $\begin{array}{l}\text { Sphingomyelin } \\
\text { Phosphodi- } \\
\text { esterase } 3\end{array}$ & & & & & & & HP & Haptoglobin \\
\hline & & & & TAPT1 & $\begin{array}{l}\text { Transmembrane } \\
\text { Anterior } \\
\text { Posterior Trans- } \\
\text { formation 1 }\end{array}$ & & & & & & & HPR & $\begin{array}{l}\text { Haptoglobin- } \\
\text { Related } \\
\text { Protein }\end{array}$ \\
\hline
\end{tabular}


Table 3. Cont

\begin{tabular}{|c|c|c|c|c|c|c|c|c|c|c|c|c|c|}
\hline \multicolumn{14}{|c|}{ Protein Expressed in Each Group of TMJ Disc Sample $(n=379)$} \\
\hline \multicolumn{2}{|c|}{$\begin{array}{l}\text { DDWoR } \\
(n=66)\end{array}$} & \multicolumn{2}{|c|}{$\mathrm{MD}(n=38)$} & \multicolumn{2}{|c|}{$\mathrm{CH}(n=89)$} & \multicolumn{2}{|c|}{ DDWoR and MD $(n=9)$} & \multicolumn{2}{|c|}{ DDWoR and $\mathrm{CH}(n=28)$} & \multicolumn{2}{|c|}{ MD and CH $(n=17)$} & \multicolumn{2}{|c|}{$\begin{array}{c}\text { DDWoR, MD and CH } \\
(n=132)\end{array}$} \\
\hline \multirow[t]{14}{*}{ Code } & Name & Code & Name & Code & Name & Code & Name & Code & Name & Code & Name & Code & Name \\
\hline & & & & TBX22 & $\begin{array}{c}\text { T-Box } \\
\text { Transcription } \\
\text { Factor } 22\end{array}$ & & & & & & & HSPB1 & $\begin{array}{c}\text { Heat Shock } \\
\text { Protein Family B } \\
\text { (Small) } \\
\text { Member } 1\end{array}$ \\
\hline & & & & TDRD1 & $\begin{array}{l}\text { Tudor Domain } \\
\text { Containing } 1\end{array}$ & & & & & & & IGHA1 & $\begin{array}{c}\text { Immunoglobulin } \\
\text { Heavy Constant } \\
\text { Alpha } 1\end{array}$ \\
\hline & & & & TENM4 & $\begin{array}{c}\text { Teneurin } \\
\text { Transmembrane } \\
\text { Protein } 4\end{array}$ & & & & & & & IGHA2 & $\begin{array}{c}\text { Immunoglobulin } \\
\text { Heavy Constant } \\
\text { Alpha 2 (A2m } \\
\text { Marker) }\end{array}$ \\
\hline & & & & THBS1 & Thrombospondin 1 & & & & & & & IGHG1 & $\begin{array}{c}\text { Immunoglobulin } \\
\text { Heavy Constant } \\
\text { Gamma 1 (G1m } \\
\text { Marker) }\end{array}$ \\
\hline & & & & TJP2 & $\begin{array}{l}\text { Tight Junction } \\
\text { Protein } 2\end{array}$ & & & & & & & IGHG2 & $\begin{array}{c}\text { Immunoglobulin } \\
\text { Heavy Constant } \\
\text { Gamma 2 (G2m } \\
\text { Marker) }\end{array}$ \\
\hline & & & & TTR & Transthyretin & & & & & & & IGHG3 & $\begin{array}{c}\text { Immunoglobulin } \\
\text { Heavy Constant } \\
\text { Gamma 3 (G3m } \\
\text { Marker) }\end{array}$ \\
\hline & & & & UBP1 & $\begin{array}{l}\text { Upstream } \\
\text { Binding } \\
\text { Protein } 1\end{array}$ & & & & & & & IGHG4 & $\begin{array}{c}\text { Immunoglobulin } \\
\text { Heavy Constant } \\
\text { Gamma } 4 \text { (G4m } \\
\text { Marker) }\end{array}$ \\
\hline & & & & WHRN & Whirlin & & & & & & & IGKC & $\begin{array}{l}\text { Immunoglobulin } \\
\text { Kappa Constant }\end{array}$ \\
\hline & & & & ZNF155 & $\begin{array}{l}\text { Zinc Finger } \\
\text { Protein } 155\end{array}$ & & & & & & & INA & $\begin{array}{c}\text { Internexin } \\
\text { Neuronal } \\
\text { Intermediate } \\
\text { Filament Protein } \\
\text { Alpha }\end{array}$ \\
\hline & & & & ZNF221 & $\begin{array}{l}\text { Zinc Finger } \\
\text { Protein } 221 \\
\end{array}$ & & & & & & & KRT7 & Keratin 7 \\
\hline & & & & & & & & & & & & KRT8 & Keratin 8 \\
\hline & & & & & & & & & & & & KRT84 & Keratin 84 \\
\hline & & & & & & & & & & & & LGALS1 & Galectin 1 \\
\hline
\end{tabular}


Table 3. Cont

\begin{tabular}{|c|c|c|c|c|c|c|c|c|c|c|c|c|c|}
\hline \multicolumn{14}{|c|}{ Protein Expressed in Each Group of TMJ Disc Sample $(n=379)$} \\
\hline \multicolumn{2}{|c|}{$\begin{array}{c}\text { DDWoR } \\
(n=66)\end{array}$} & \multicolumn{2}{|c|}{$\mathrm{MD}(n=38)$} & \multicolumn{2}{|c|}{$\mathrm{CH}(n=89)$} & \multicolumn{2}{|c|}{ DDWoR and MD $(n=9)$} & \multicolumn{2}{|c|}{ DDWoR and $\mathrm{CH}(n=28)$} & \multicolumn{2}{|c|}{$\mathrm{MD}$ and $\mathrm{CH}(n=17)$} & \multicolumn{2}{|c|}{$\begin{array}{c}\text { DDWoR, MD and CH } \\
(n=132)\end{array}$} \\
\hline \multirow[t]{16}{*}{ Code } & Name & Code & Name & Code & Name & Code & Name & Code & Name & Code & Name & Code & Name \\
\hline & & & & & & & & & & & & LMNA & Lamin A/C \\
\hline & & & & & & & & & & & & LUM & Lumican \\
\hline & & & & & & & & & & & & MFAP4 & $\begin{array}{l}\text { Microfibril } \\
\text { Associated } \\
\text { Protein } 4\end{array}$ \\
\hline & & & & & & & & & & & & MFGE8 & $\begin{array}{c}\text { Milk Fat Globule } \\
\text { EGF And Factor } \\
\text { V/VIII Domain } \\
\text { Containing }\end{array}$ \\
\hline & & & & & & & & & & & & MYH16 & $\begin{array}{c}\text { Myosin Heavy } \\
\text { Chain } 16 \\
\text { Pseudogene }\end{array}$ \\
\hline & & & & & & & & & & & & MYOC & Myocilin \\
\hline & & & & & & & & & & & & NEFH & $\begin{array}{l}\text { Neurofilament } \\
\text { Heavy }\end{array}$ \\
\hline & & & & & & & & & & & & NEFL & $\begin{array}{c}\text { Neurofilament } \\
\text { Light }\end{array}$ \\
\hline & & & & & & & & & & & & OGN & Osteoglycin \\
\hline & & & & & & & & & & & & POTEE & $\begin{array}{l}\text { POTE Ankyrin } \\
\text { Domain Family } \\
\text { Member E }\end{array}$ \\
\hline & & & & & & & & & & & & POTEF & $\begin{array}{l}\text { POTE Ankyrin } \\
\text { Domain Family } \\
\text { Member F }\end{array}$ \\
\hline & & & & & & & & & & & & POTEI & $\begin{array}{l}\text { POTE Ankyrin } \\
\text { Domain Family } \\
\text { Member I }\end{array}$ \\
\hline & & & & & & & & & & & & POTEJ & $\begin{array}{l}\text { POTE Ankyrin } \\
\text { Domain Family } \\
\text { Member J }\end{array}$ \\
\hline & & & & & & & & & & & & POTEKP & $\begin{array}{c}\text { POTE Ankyrin } \\
\text { Domain Family } \\
\text { Member K, } \\
\text { Pseudogene }\end{array}$ \\
\hline & & & & & & & & & & & & PPIA & $\begin{array}{l}\text { Peptidylprolyl } \\
\text { Isomerase A }\end{array}$ \\
\hline
\end{tabular}


Table 3. Cont

\begin{tabular}{|c|c|c|c|c|c|c|c|c|c|c|c|c|c|}
\hline \multicolumn{14}{|c|}{ Protein Expressed in Each Group of TMJ Disc Sample $(n=379)$} \\
\hline \multicolumn{2}{|c|}{$\begin{array}{c}\text { DDWoR } \\
(n=66)\end{array}$} & \multicolumn{2}{|c|}{ MD $(n=38)$} & \multicolumn{2}{|c|}{$\mathrm{CH}(n=89)$} & \multicolumn{2}{|c|}{ DDWoR and MD $(n=9)$} & \multicolumn{2}{|c|}{ DDWoR and CH $(n=28)$} & \multicolumn{2}{|c|}{ MD and $\mathrm{CH}(n=17)$} & \multicolumn{2}{|c|}{$\begin{array}{c}\text { DDWoR, MD and CH } \\
(n=132)\end{array}$} \\
\hline \multirow[t]{17}{*}{ Code } & Name & Code & Name & Code & Name & Code & Name & Code & Name & Code & Name & Code & Name \\
\hline & & & & & & & & & & & & PRDX2 & Peroxiredoxin 2 \\
\hline & & & & & & & & & & & & PRELP & $\begin{array}{l}\text { Proline And } \\
\text { Arginine Rich } \\
\text { End Leucine } \\
\text { Rich Repeat } \\
\text { Protein }\end{array}$ \\
\hline & & & & & & & & & & & & PRPH & Peripherin \\
\hline & & & & & & & & & & & & RPL7L1 & $\begin{array}{c}\text { Ribosomal } \\
\text { Protein L7 Like } 1\end{array}$ \\
\hline & & & & & & & & & & & & S100A10 & $\begin{array}{l}\text { S100 Calcium } \\
\text { Binding Protein } \\
\text { A10 }\end{array}$ \\
\hline & & & & & & & & & & & & SALL3 & $\begin{array}{l}\text { Spalt Like } \\
\text { Transcription } \\
\text { Factor } 3\end{array}$ \\
\hline & & & & & & & & & & & & SHLD3 & $\begin{array}{l}\text { Shieldin } \\
\text { Complex } \\
\text { Subunit } 3\end{array}$ \\
\hline & & & & & & & & & & & & SLC4A1 & $\begin{array}{c}\text { Solute Carrier } \\
\text { Family } 4 \\
\text { Member } 1 \\
\end{array}$ \\
\hline & & & & & & & & & & & & SOD3 & $\begin{array}{l}\text { Superoxide } \\
\text { Dismutase } 3\end{array}$ \\
\hline & & & & & & & & & & & & TF & Transferrin \\
\hline & & & & & & & & & & & & TGFBI & $\begin{array}{l}\text { Transforming } \\
\text { Growth Factor } \\
\text { Beta Induced } \\
\end{array}$ \\
\hline & & & & & & & & & & & & THBS4 & Thrombospondin 4 \\
\hline & & & & & & & & & & & & TNC & Tenascin C \\
\hline & & & & & & & & & & & & TNXA & $\begin{array}{c}\text { Tenascin XA } \\
\text { (Pseudogene) }\end{array}$ \\
\hline & & & & & & & & & & & & TNXB & Tenascin XB \\
\hline & & & & & & & & & & & & TUBA1A & Tubulin Alpha 1a \\
\hline
\end{tabular}


Table 3. Cont

\begin{tabular}{|c|c|c|c|c|c|c|c|c|c|c|c|c|c|}
\hline \multicolumn{14}{|c|}{ Protein Expressed in Each Group of TMJ Disc Sample $(n=379)$} \\
\hline \multicolumn{2}{|c|}{$\begin{array}{c}\text { DDWoR } \\
(n=66)\end{array}$} & \multicolumn{2}{|c|}{$\operatorname{MD}(n=38)$} & \multicolumn{2}{|c|}{$\mathrm{CH}(n=89)$} & \multicolumn{2}{|c|}{ DDWoR and MD $(n=9)$} & \multicolumn{2}{|c|}{ DDWoR and $\mathrm{CH}(n=28)$} & \multicolumn{2}{|c|}{$\mathrm{MD}$ and $\mathrm{CH}(n=17)$} & \multicolumn{2}{|c|}{$\begin{array}{c}\text { DDWoR, MD and CH } \\
(n=132)\end{array}$} \\
\hline Code & Name & Code & Name & Code & Name & Code & Name & Code & Name & Code & Name & Code & Name \\
\hline & & & & & & & & & & & & TUBA1C & Tubulin Alpha 1 \\
\hline & & & & & & & & & & & & TUBA3E & Tubulin Alpha 3 \\
\hline & & & & & & & & & & & & TUBA4A & Tubulin Alpha 4 \\
\hline & & & & & & & & & & & & TUBA8 & Tubulin Alpha 8 \\
\hline & & & & & & & & & & & & TUBB & $\begin{array}{l}\text { Tubulin Beta } \\
\text { Class I } \\
\end{array}$ \\
\hline & & & & & & & & & & & & TUBB1 & $\begin{array}{c}\text { Tubulin Beta } 1 \\
\text { Class VI }\end{array}$ \\
\hline & & & & & & & & & & & & TUBB2A & $\begin{array}{l}\text { Tubulin Beta 2A } \\
\text { Class IIa }\end{array}$ \\
\hline & & & & & & & & & & & & TUBB2B & $\begin{array}{c}\text { Tubulin Beta 2B } \\
\text { Class IIb }\end{array}$ \\
\hline & & & & & & & & & & & & TUBB3 & $\begin{array}{c}\text { Tubulin Beta } 3 \\
\text { Class III }\end{array}$ \\
\hline & & & & & & & & & & & & TUBв4B & $\begin{array}{c}\text { Tubulin Beta 4B } \\
\text { Class IVb }\end{array}$ \\
\hline & & & & & & & & & & & & TUBB6 & $\begin{array}{c}\text { Tubulin Beta } 6 \\
\text { Class V }\end{array}$ \\
\hline & & & & & & & & & & & & TUBB8 & $\begin{array}{c}\text { Tubulin Beta } 8 \\
\text { Class VIII }\end{array}$ \\
\hline & & & & & & & & & & & & TUBB8B & Tubulin Beta 8B \\
\hline
\end{tabular}


Table 4. Proteins expressed in both synovial fluid and TMJ disc samples of each group.

\begin{tabular}{|c|c|c|c|c|c|c|}
\hline \multicolumn{7}{|c|}{ Protein Expressed in Each Group of TMJ Synovial Fluid and Disc Samples $(n=11)$} \\
\hline DDWoR $(n=2)$ & $\operatorname{MD}(n=3)$ & $\mathrm{CH}(n=0)$ & $\begin{array}{l}\text { DDWoR and } \\
\operatorname{MD}(n=0)\end{array}$ & $\begin{array}{c}\text { DDWoR and } \\
\text { CH }(n=0)\end{array}$ & MD and $\mathrm{CH}(n=0)$ & $\begin{array}{l}\text { DDWoR, MD } \\
\text { and } \mathrm{CH}(n=6)\end{array}$ \\
\hline CHD8 & FLNA & & & & & ENO1 \\
\hline \multirow[t]{5}{*}{ MYL6B } & PPFIA1 & & & & & ENO2 \\
\hline & PPFIA2 & & & & & ENO3 \\
\hline & & & & & & MYH16 \\
\hline & & & & & & RPL7L1 \\
\hline & & & & & & SHLD3 \\
\hline
\end{tabular}

Table 5. Gene code, protein name and function for each sample of TMJ synovial fluid.

\begin{tabular}{|c|c|c|}
\hline \multicolumn{3}{|c|}{ Synovial Fluid Sample } \\
\hline Code & Name & Function \\
\hline \multicolumn{3}{|c|}{ DDWoR } \\
\hline $\mathrm{A} 2 \mathrm{M}$ & Alpha-2-Macroglobulin & Inhibits inflammatory cytokines. \\
\hline APCS & Amyloid P Component, Serum & Binds to apoptotic cells at an early stage. \\
\hline GPSM2 & G Protein Signaling Modulator 2 & Involved in the development of normal hearing. \\
\hline KRT18 & Keratin 18 & Is involved in interleukin-6-mediated barrier protection. \\
\hline MAP3K7 & Mitogen-Activated Protein Kinase Kinase Kinase 7 & $\begin{array}{l}\text { Mediates signal transduction various cytokines including } \\
\text { interleukin-1, transforming growth factor-beta, bone } \\
\text { morphogenetic protein } 2 \text { and } 4 \text {, Toll-like receptors, tumor } \\
\text { necrosis factor receptor CD } 40 \text { and B-cell receptor. }\end{array}$ \\
\hline SERPINC1 & Serpin Family C Member 1 & $\begin{array}{l}\text { This protein inhibits thrombin and it regulates the blood } \\
\text { coagulation cascade. }\end{array}$ \\
\hline \multicolumn{3}{|c|}{ MD } \\
\hline ALDH1L1 & Aldehyde Dehydrogenase 1 Family Member L1 & $\begin{array}{l}\text { Associated with decreased apoptosis, increased cell motility, } \\
\text { and cancer progression. }\end{array}$ \\
\hline $\mathrm{C} 4 \mathrm{~A}$ & Complement C4A (Rodgers Blood Group) & $\begin{array}{l}\text { An antimicrobial peptide and a mediator of } \\
\text { local inflammation. }\end{array}$ \\
\hline HPX & Hemopexin & $\begin{array}{l}\text { Acute phase protein that transports heme from the plasma } \\
\text { to the liver and may be involved in protecting cells from } \\
\text { oxidative stress. }\end{array}$ \\
\hline IFT122 & Intraflagellar Transport 122 & $\begin{array}{c}\text { Involved in cell cycle progression, signal transduction, } \\
\text { apoptosis, and gene regulation. }\end{array}$ \\
\hline MYO6 & Myosin VI & $\begin{array}{l}\text { This protein maintains the structural integrity of inner ear } \\
\text { hair cells and mutations in this gene cause hearing loss. }\end{array}$ \\
\hline PRDX1 & Peroxiredoxin 1 & $\begin{array}{l}\text { Has an antioxidant protective role in cells and may } \\
\text { contribute to the antiviral activity of CD8(+) T-cells. }\end{array}$ \\
\hline SERPINH1 & Serpin Family H Member 1 & $\begin{array}{l}\text { Plays a role in collagen biosynthesis as a collagen-specific } \\
\text { molecular chaperone. }\end{array}$ \\
\hline SMPD3 & Sphingomyelin Phosphodiesterase 3 & $\begin{array}{l}\text { Mediates cellular functions, such as apoptosis and } \\
\text { growth arrest. }\end{array}$ \\
\hline \multicolumn{3}{|c|}{$\mathrm{CH}$} \\
\hline ADH1 & Alcohol Dehydrogenase Subunit Alpha & Catalyzes the oxidation of alcohols to aldehydes. \\
\hline \multicolumn{3}{|c|}{ DDWoR and MD } \\
\hline ANXA1 & Annexin A1 & $\begin{array}{l}\text { Inhibits phospholipase A2 and has } \\
\text { anti-inflammatory activity. }\end{array}$ \\
\hline
\end{tabular}


Table 5. Cont.

\section{Synovial Fluid Sample}

$\begin{array}{lll}\text { Code Name Function } & \text { Fan }\end{array}$

\section{$\mathrm{CH}$}

DDWoR and MD

\begin{tabular}{|c|c|c|}
\hline ANXA2 & Annexin A2 & $\begin{array}{c}\text { Functions as an autocrine factor which heightens osteoclast } \\
\text { formation and bone resorption. }\end{array}$ \\
\hline ASPN & Asporin & $\begin{array}{l}\text { Regulate chondrogenesis by inhibiting transforming growth } \\
\text { factor-beta 1-induced gene expression in cartilage. May } \\
\text { induce collagen mineralization. }\end{array}$ \\
\hline BGN & Biglycan & $\begin{array}{l}\text { Plays a role in bone growth, muscle development and } \\
\text { regeneration, and collagen fibril assembly in multiple } \\
\text { tissues. This protein may also regulate inflammation and } \\
\text { innate immunity. }\end{array}$ \\
\hline CILP & Cartilage Intermediate Layer Protein & $\begin{array}{l}\text { This protein is present in the cartilage intermediate layer } \\
\text { protein (CILP), which increases in early } \\
\text { osteoarthrosis cartilage. }\end{array}$ \\
\hline CLU & Clusterin & $\begin{array}{l}\text { Under stress conditions can be found in the cell cytosol. } \\
\text { May be involved in cell death, tumor progression, and } \\
\text { neurodegenerative disorders }\end{array}$ \\
\hline COMP & Thrombospondin-5 & $\begin{array}{c}\text { Present in rheumatoid arthritis, is a noncollagenous } \\
\text { extracellular matrix protein. }\end{array}$ \\
\hline $\mathrm{DCN}$ & Decorin & $\begin{array}{l}\text { Has a stimulatory effect on autophagy and inflammation } \\
\text { and an inhibitory effect on angiogenesis and tumorigenesis. }\end{array}$ \\
\hline FMOD & Fibromodulin & $\begin{array}{l}\text { May also regulate TGF-beta activities by sequestering } \\
\text { TGF-beta into the extracellular matrix. }\end{array}$ \\
\hline FN1 & Fibronectin 1 & $\begin{array}{l}\text { Fibronectin is involved in cell adhesion and migration } \\
\text { processes including embryogenesis, wound healing, blood } \\
\text { coagulation, host defense. }\end{array}$ \\
\hline IGHG1 & $\begin{array}{l}\text { Immunoglobulin Heavy Constant Gamma } 1 \\
\text { (G1m Marker) }\end{array}$ & $\begin{array}{c}\text { Involved in pathways of Interleukin- } 4 \text { and } 13 \text { signaling and } \\
\text { IL4-mediated signaling events. }\end{array}$ \\
\hline \multicolumn{3}{|c|}{ DDWoR and $\mathrm{CH}$} \\
\hline $\mathrm{x}$ & $\mathrm{x}$ & $\mathrm{x}$ \\
\hline \multicolumn{3}{|c|}{$\mathrm{MD}$ and $\mathrm{CH}$} \\
\hline $\mathrm{x}$ & $\mathrm{x}$ & $\mathrm{x}$ \\
\hline \multicolumn{3}{|c|}{ DDWoR, MD and CH } \\
\hline $\mathrm{ENO} 2$ & Enolase 2 & Found in mature neurons and cells of neuronal origin. \\
\hline ENO3 & Enolase 3 & May play a role in muscle development and regeneration. \\
\hline
\end{tabular}

Table 6. Gene code, protein name and function for each sample of TMJ discs.

\begin{tabular}{ccc}
\hline & \multicolumn{2}{c}{ Disc Sample } \\
\hline Code & Name & Fownction \\
\hline & \multicolumn{2}{c}{ DDoR } \\
\hline AMBP & Alpha-1-Microglobulin/Bikunin Precursor & Regulation of the inflammatory process. \\
\hline MMP10 & Matrix Metallopeptidase 10 & Breakdown of extracellular matrix. \\
\hline MMP27 & Matrix Metallopeptidase 27 & Breakdown of extracellular matrix. \\
\hline MMP3 & Matrix Metallopeptidase 3 & Breakdown of extracellular matrix. \\
\hline PLA2G7 & Phospholipase A2 Group VII & Inflammatory and oxidative stress response.
\end{tabular}


Table 6. Cont.

\begin{tabular}{|c|c|c|}
\hline \multicolumn{3}{|c|}{ Disc Sample } \\
\hline Code & Name & Function \\
\hline \multicolumn{3}{|c|}{ DDWoR } \\
\hline THADA & THADA Armadillo Repeat Containing & Apoptosis pathway. \\
\hline THBS3 & Thrombospondin 3 & Matrix interactions. \\
\hline \multicolumn{3}{|c|}{ MD } \\
\hline AKAP13 & A-kinase anchor protein 13 & Regulation of apoptotic process. \\
\hline CCDC88A & Girdin & Vascular endothelial growth factor receptor 2 binding. \\
\hline COL4A1 & Collagen alpha-1(IV) chain & Extracellular matrix structural constituent. \\
\hline ERAS & GTPase ERas & Tumor-like growth properties of embryonic stem cells. \\
\hline ERBIN & Erbin & $\begin{array}{l}\text { Inhibits NOD2-dependent NF-kappa-B signaling and } \\
\text { proinflammatory cytokine secretion. }\end{array}$ \\
\hline PARP10 & Protein mono-ADP-ribosyltransferase PARP10 & Negative regulation of fibroblast proliferation. \\
\hline PPFIA1 & Liprin-alpha-1 & Cell-matrix adhesion. \\
\hline PPFIA2 & Liprin-alpha-2 & Cell-matrix adhesion. \\
\hline PTPN7 & Tyrosine-protein phosphatase non-receptor type 7 & $\begin{array}{l}\text { Regulation of T and B-lymphocyte development and } \\
\text { signal transduction. }\end{array}$ \\
\hline UPK3A & Uroplakin-3a & Epithelial cell differentiation. \\
\hline \multicolumn{3}{|c|}{$\mathrm{CH}$} \\
\hline ACTN4 & Actinin Alpha 4 & Transcriptional coactivator. \\
\hline ADAM10 & ADAM Metallopeptidase Domain 10 & Responsible for the FasL ectodomain shedding. \\
\hline COQ8B & Coenzyme Q8B & Biosynthesis of coenzyme Q. \\
\hline HPX & Hemopexin & Protect cells from oxidative stress. \\
\hline HSPA1A & Heat Shock Protein Family A (Hsp70) Member 1A & Protection of the proteome from stress. \\
\hline NEK10 & NIMA Related Kinase 10 & Cellular response to UV irradiation. \\
\hline PDLIM4 & PDZ And LIM Domain 4 & Involved in bone development. \\
\hline SERPINH1 & Serpin Family H Member 1 & Chaperone in the biosynthetic pathway of collagen. \\
\hline TTR & Transthyretin & Thyroid hormone-binding protein. \\
\hline COL1A2 & Collagen Type I Alpha 2 Chain & Fibril-forming collagen abundant in bone. \\
\hline PRG4 & Proteoglycan 4 & $\begin{array}{l}\text { This protein contains both chondroitin sulfate and keratan } \\
\text { sulfate glycosaminoglycans. }\end{array}$ \\
\hline PTPN13 & $\begin{array}{c}\text { Protein Tyrosine Phosphatase Non-Receptor } \\
\text { Type } 13\end{array}$ & Regulates negatively FasL induced apoptosis. \\
\hline \multicolumn{3}{|c|}{ DDWoR and MD } \\
\hline $\mathrm{C} 4 \mathrm{~A}$ & Complement $\mathrm{C} 4 \mathrm{~A}$ & Antimicrobial peptide and a mediator of local inflammation. \\
\hline $\mathrm{C} 4 \mathrm{~B}$ & Complement C4B & Mediator of local inflammation. \\
\hline C4B_2 & Complement Component 4B & Mediator of local inflammatory process. \\
\hline SEMA4F & Semaphorin $4 \mathrm{~F}$ & Plays a role in neural development. \\
\hline Code & Name & Function \\
\hline
\end{tabular}

DDWoR and $\mathrm{CH}$

ACAN

Aggrecan

Collagen Type I Alpha 1 Chain
Part of the extracellular matrix that withstands compression in cartilage.

Collagen component. 
Table 6. Cont.

\begin{tabular}{cccc}
\hline \multicolumn{4}{c}{ Disc Sample } \\
\hline Code & \multicolumn{2}{c}{ DDWoR and CH } \\
\hline COL4A6 & Collagen Type IV Alpha 6 Chain & Major structural component of basement membranes. \\
\hline HSPA2 & Heat Shock Protein Family A (Hsp70) Member 2 & Protection of the proteome from stress. \\
\hline POSTN & Periostin & $\begin{array}{c}\text { Extracellular matrix protein that functions in tissue } \\
\text { development and regeneration, including wound healing. }\end{array}$ \\
\hline
\end{tabular}

MD and $\mathrm{CH}$

\begin{tabular}{|c|c|c|}
\hline KRT6A & Keratin 6A & $\begin{array}{l}\text { Epidermis-specific type I keratin involved in wound } \\
\text { healing. }\end{array}$ \\
\hline \multicolumn{3}{|c|}{ DDWoR, MD and $\mathrm{CH}$} \\
\hline ANXA1 & Annexin A1 & Anti-inflammatory activity. \\
\hline ANXA2 & Annexin A2 & Heightens osteoclast formation and bone resorption. \\
\hline ANXA2P2 & Annexin A2 Pseudogene 2 & May be involved in heat-stress response. \\
\hline APCS & Amyloid P Component & Is involved in dealing with apoptotic cells in vivo. \\
\hline ASPN & Asporin & $\begin{array}{l}\text { Regulates chondrogenesis by inhibiting transforming } \\
\text { growth factor-beta 1-induced gene expression in cartilage }\end{array}$ \\
\hline BGN & Biglycan & $\begin{array}{l}\text { Plays a role in bone growth, and collagen fibril assembly in } \\
\text { multiple tissues. This protein may also regulate } \\
\text { inflammation and innate immunity. }\end{array}$ \\
\hline $\mathrm{C} 3$ & Complement C3 & $\begin{array}{c}\text { Modulates inflammation and possesses } \\
\text { antimicrobial activity. }\end{array}$ \\
\hline CILP & Cartilage Intermediate Layer Protein & Increases in early osteoarthrosis cartilage. \\
\hline COL12A1 & Collagen Type XII Alpha 1 Chain & Type XII collagen. \\
\hline COL14A1 & Collagen Type XIV Alpha 1 Chain & Type XIV collagen. \\
\hline COL6A1 & Collagen Type VI Alpha 1 Chain & Collagen VI. \\
\hline COL6A2 & Collagen Type VI Alpha 2 Chain & Type VI collagen. \\
\hline COL6A3 & Collagen Type VI Alpha 3 Chain & Ttype VI collagen. \\
\hline COMP & Cartilage Oligomeric Matrix Protein & Degradation of the extracellular matrix. \\
\hline ENO1 & Enolase 1 & Tumor suppressor. \\
\hline ENO2 & Enolase 2 & Found in mature neurons and cells of neuronal origin. \\
\hline ENO3 & Enolase 3 & Plays a role in muscle development and regeneration. \\
\hline FN1 & Fibronectin 1 & $\begin{array}{l}\text { Involved in wound healing, blood coagulation, } \\
\text { host defense. }\end{array}$ \\
\hline KRT7 & Keratin 7 & $\begin{array}{l}\text { Co-expressed during differentiation of simple and stratified } \\
\text { epithelial tissues. }\end{array}$ \\
\hline LUM & Lumican & $\begin{array}{l}\text { May regulate collagen fibril organization, epithelial cell } \\
\text { migration and tissue repair. }\end{array}$ \\
\hline MFAP4 & Microfibril Associated Protein 4 & $\begin{array}{l}\text { Extracellular matrix protein which is involved in cell } \\
\text { adhesion or intercellular interactions. }\end{array}$ \\
\hline MFGE8 & $\begin{array}{l}\text { Milk Fat Globule EGF And Factor V/VIII Domain } \\
\text { Containing }\end{array}$ & $\begin{array}{l}\text { Promotes phagocytosis of apoptotic cells. This protein has } \\
\text { also been implicated in wound healing, autoimmune } \\
\text { disease, and cancer. }\end{array}$ \\
\hline OGN & Osteoglycin & $\begin{array}{l}\text { Induces ectopic bone formation in conjunction with } \\
\text { transforming growth factor beta and may regulate } \\
\text { osteoblast differentiation. }\end{array}$ \\
\hline
\end{tabular}


Table 6. Cont.

\begin{tabular}{|c|c|c|}
\hline \multicolumn{3}{|c|}{ Disc Sample } \\
\hline Code & Name & Function \\
\hline \multicolumn{3}{|c|}{ MD and $\mathrm{CH}$} \\
\hline \multicolumn{3}{|c|}{ DDWoR, MD and $\mathrm{CH}$} \\
\hline SOD3 & Superoxide Dismutase 3 & $\begin{array}{l}\text { Antioxidant enzymes that protect tissues from } \\
\text { oxidative stress. }\end{array}$ \\
\hline TGFBI & Transforming Growth Factor Beta Induced & $\begin{array}{l}\text { May be involved in endochondrial bone formation } \\
\text { in cartilage. }\end{array}$ \\
\hline TNC & Tenascin C & Modulation of inflammatory cytokine. \\
\hline TNXB & Tenascin XB & Accelerates collagen fibril formation. \\
\hline VCAN & Versican & $\begin{array}{l}\text { A large chondroitin sulfate proteoglycan and is a major } \\
\text { component of the extracellular matrix. }\end{array}$ \\
\hline VIM & Vimentin & $\begin{array}{l}\text { Involved in the stabilization of type I collagen mRNAs for } \\
\qquad \text { CO1A1 and CO1A2. }\end{array}$ \\
\hline
\end{tabular}

The disc sample presented the following protein functions for each group (Table 6): the DDWoR group expressed proteins involved in inflammatory process, neurogenesis, cartilage formation, extracellular matrix degradation, oxidative stress and apoptosis. The MD group presented proteins related to apoptosis, vascular growth, inflammatory inhibitors, immunologic factors and epithelial growth, and the $\mathrm{CH}$ group showed protein expression implicated in apoptosis, apoptosis inhibition, oxidative stress, bone formation, chondroitin, bone and cartilage formation. The group with DDWoR and MD samples had proteins involved in inflammatory process; the group with DDWoR and $\mathrm{CH}$ samples showed proteins with collagen formation and wound healing functions; the group with $\mathrm{MD}$ and $\mathrm{CH}$ was involved in wound healing; and the group containing DDWoR, MD and CH samples was involved with inflammatory cascade modulation, osteoclastogenesis, chondrogenesis, apoptosis, bone formation, vascular and tissue repair, antioxidative activity.

There were proteins identified in both synovial fluid and TMJ disc samples, however, some of them in different pathology groups (Table 7).

Table 7. Name and function of expressed proteins in common between synovial fluid and TMJ disc sample, and the groups in each protein was expressed.

\begin{tabular}{cccc}
\hline Name & Function & Disc & Synovial Fluid \\
\hline Amyloid P Component, Serum & $\begin{array}{c}\text { Is involved in dealing with apoptotic } \\
\text { cells in vivo. }\end{array}$ & DDWoR, MD and CH & DDWoR \\
\hline Annexin A1 & Anti-inflammatory activity. & DDWoR, MD and CH & DDWoR and MD \\
\hline Annexin A2 & $\begin{array}{c}\text { Heightens osteoclast formation and } \\
\text { bone resorption. }\end{array}$ & DDWoR, MD and CH & DDWoR and MD \\
\hline Asporin & Regulates chondrogenesis. & DDWoR, MD and CH & DDWoR and MD \\
\hline Biglycan & $\begin{array}{c}\text { Plays a role in bone growth, and } \\
\text { collagen fibril assembly in } \\
\text { multiple tissues. }\end{array}$ & DDWoR, MD and CH & DDWoR and MD \\
\hline Cartilage Intermediate Layer Protein & $\begin{array}{c}\text { Increases in early } \\
\text { osteoarthrosis cartilage. }\end{array}$ & DDWoR, MD and CH & DDWoR and MD \\
\hline Complement C4A & $\begin{array}{c}\text { Antimicrobial peptide and a mediator } \\
\text { of local inflammation. }\end{array}$ & DDWoR and MD & DDWoR, MD and CH \\
\hline Enolase 2 & $\begin{array}{c}\text { Found in mature neurons and cells of } \\
\text { neuronal origin. }\end{array}$ & DD, MD and CH \\
\hline
\end{tabular}


Table 7. Cont.

\begin{tabular}{|c|c|c|c|}
\hline Name & Function & Disc & Synovial Fluid \\
\hline Enolase 3 & $\begin{array}{l}\text { Play a role in muscle development } \\
\text { and regeneration. }\end{array}$ & DDWoR, MD and $\mathrm{CH}$ & DDWoR, MD and $\mathrm{CH}$ \\
\hline Fibronectin 1 & $\begin{array}{l}\text { Involved in wound healing, blood } \\
\text { coagulation, host defense. }\end{array}$ & DDWoR, $\mathrm{MD}$ and $\mathrm{CH}$ & DDWoR and MD \\
\hline Hemopexin & Protect cells from oxidative stress. & $\mathrm{CH}$ & MD \\
\hline Lumican & $\begin{array}{l}\text { May regulate collagen fibril } \\
\text { organization, epithelial cell migration } \\
\text { and tissue repair. }\end{array}$ & DDWoR, MD and $\mathrm{CH}$ & DDWoR and MD \\
\hline Osteoglycin & Regulate osteoblast differentiation. & DDWoR, MD and CH & DDWoR and MD \\
\hline Serpin Family H Member 1 & $\begin{array}{l}\text { Chaperones in the biosynthetic } \\
\text { pathway of collagen. }\end{array}$ & $\mathrm{CH}$ & MD \\
\hline Superoxide Dismutase 3 & $\begin{array}{l}\text { Antioxidant enzymes that protect } \\
\text { tissues from oxidative stress. }\end{array}$ & DDWoR, MD and $\mathrm{CH}$ & DDWoR and MD \\
\hline Tenascin XB & Modulation of inflammatory cytokine. & DDWoR, MD and $\mathrm{CH}$ & DDWoR and MD \\
\hline $\begin{array}{l}\text { Transforming Growth Factor } \\
\text { Beta Induced }\end{array}$ & $\begin{array}{l}\text { May be involved in endochondral bone } \\
\text { formation in cartilage. }\end{array}$ & DDWoR, MD and $\mathrm{CH}$ & DDWoR and MD \\
\hline Versican & $\begin{array}{l}\text { A large chondroitin sulfate } \\
\text { proteoglycan and is a major component } \\
\text { of the extracellular matrix. }\end{array}$ & DDWoR, MD and $\mathrm{CH}$ & DDWoR and MD \\
\hline
\end{tabular}

Different types of collagen were identified in discs of the MD group, $\mathrm{CH}$ group, DDWoR and $\mathrm{CH}$ group, and in the group with all pathologies together (DDWoR, MD and $\mathrm{CH}$ ). Besides the known collagen type I present in TMJ discs, collagen type IV, VI, XII and XIV were also identified (Table 8).

Table 8. Types of collagen identified in each TMJ disc group.

\begin{tabular}{|c|c|c|c|c|c|c|c|c|c|c|}
\hline \multicolumn{11}{|c|}{ Type of Collagen Identified in Each Group } \\
\hline \multirow{2}{*}{$\begin{array}{c}\text { DDWoR } \\
\mathbf{x}\end{array}$} & \multicolumn{2}{|r|}{ MD } & \multicolumn{2}{|r|}{$\mathrm{CH}$} & \multirow{2}{*}{$\begin{array}{c}\text { DDWoR } \\
\text { and MD }\end{array}$} & \multicolumn{2}{|c|}{ DDWoR and CH } & \multirow{2}{*}{$\begin{array}{c}\text { MD } \\
\text { and } \mathrm{CH} \\
x\end{array}$} & \multicolumn{2}{|c|}{ DDWoR, MD and CH } \\
\hline & Code & Name & Code & Name & & Code & Name & & Code & Name \\
\hline & COL4A1 & $\begin{array}{c}\text { Collagen Type } \\
\text { IV Alpha } 1 \\
\text { Chain }\end{array}$ & COL1A2 & $\begin{array}{c}\text { Collagen } \\
\text { Type I Alpha } \\
2 \text { Chain }\end{array}$ & & COL1A1 & $\begin{array}{l}\text { Collagen } \\
\text { Type I } \\
\text { Alpha } 1 \\
\text { Chain }\end{array}$ & & COL12A1 & $\begin{array}{c}\text { Collagen Type } \\
\text { XII Alpha } 1 \\
\text { Chain }\end{array}$ \\
\hline & & & & & & COL4A6 & $\begin{array}{c}\text { Collagen } \\
\text { Type IV } \\
\text { Alpha } 6 \\
\text { Chain }\end{array}$ & & COL14A1 & $\begin{array}{c}\text { Collagen Type } \\
\text { XIV Alpha } 1 \\
\text { Chain }\end{array}$ \\
\hline & & & & & & & & & COL6A1 & $\begin{array}{c}\text { Collagen Type } \\
\text { VI Alpha } 1 \\
\text { Chain }\end{array}$ \\
\hline & & & & & & & & & COL6A2 & $\begin{array}{c}\text { Collagen Type } \\
\text { VI Alpha } 2 \\
\text { Chain }\end{array}$ \\
\hline & & & & & & & & & COL6A3 & $\begin{array}{c}\text { Collagen Type } \\
\text { VI Alpha } 3 \\
\text { Chain }\end{array}$ \\
\hline
\end{tabular}

All shared and group-specific proteins are indicated in a Venn diagram for the synovial fluid (Figure 1) and disc samples (Figure 2). 


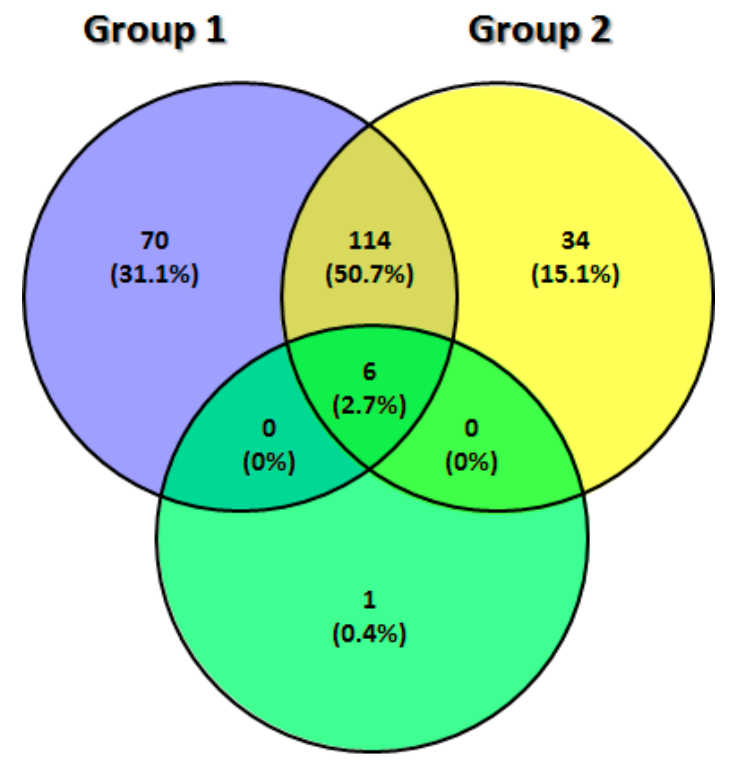

Group 3

Figure 1. Venn diagram for synovial fluid: group $1-\mathrm{DDWoR}$, group $2-\mathrm{MD}$, group $3-\mathrm{CH}$.

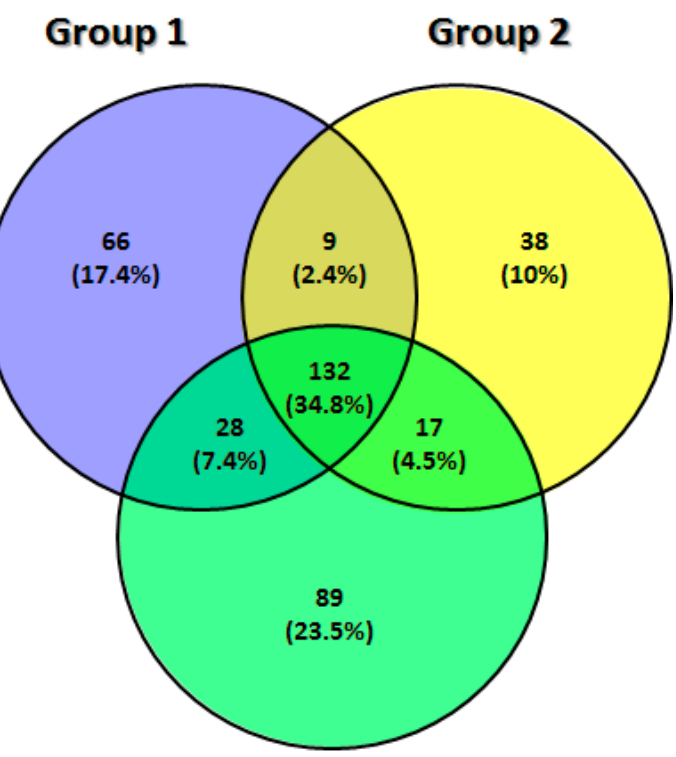

Group 3

Figure 2. Venn diagram for the TMJ disc: group $1-\mathrm{DDW}$, group $2-\mathrm{MD}$, group $3-\mathrm{CH}$.

The interactions between the proteins were analyzed with Genemania (https:// genemania.org-accessed on 5 September 2020), and its genetic network pointed out distinct protein cascades that might be modulating each pathology through the synovial fluid and disc samples. The physical and genetic interactions, co-expression and pathway of the proteins are shown in Figures 3 and 4. 


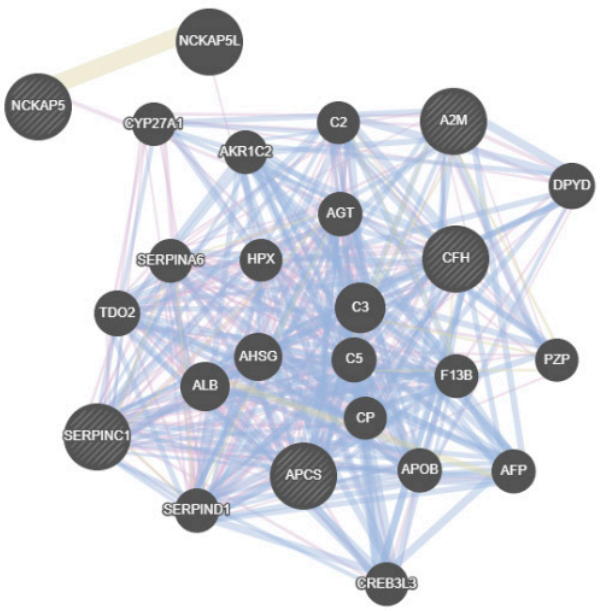

(A)

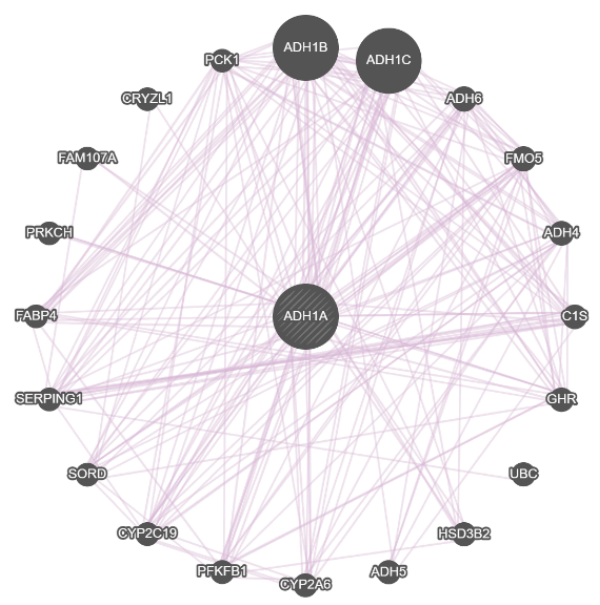

(C)

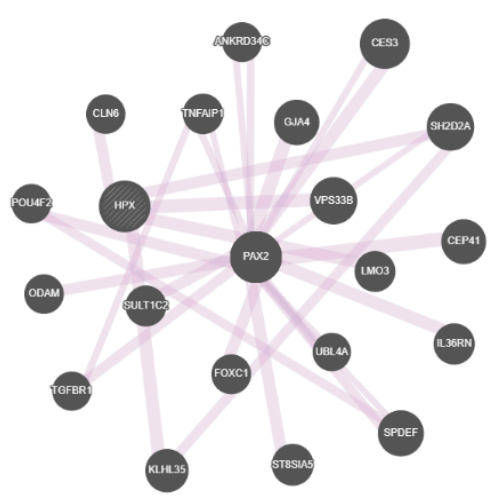

(B)

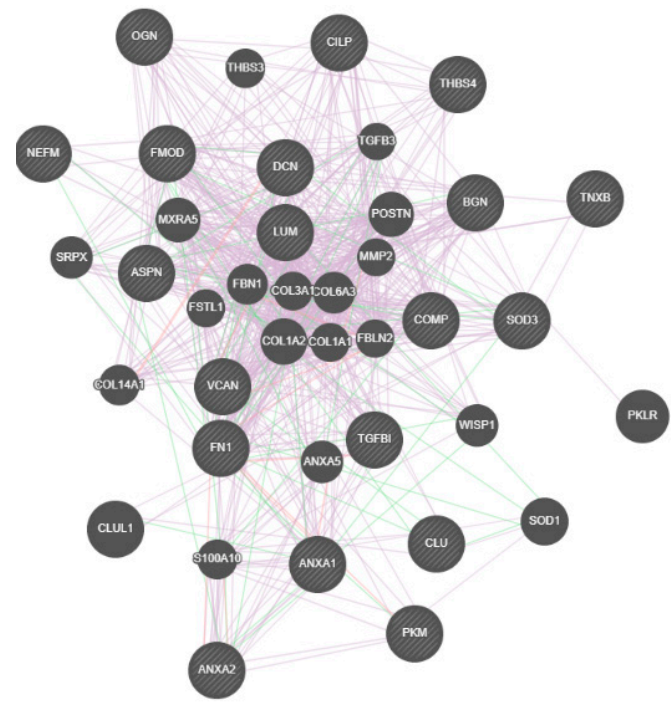

(D)

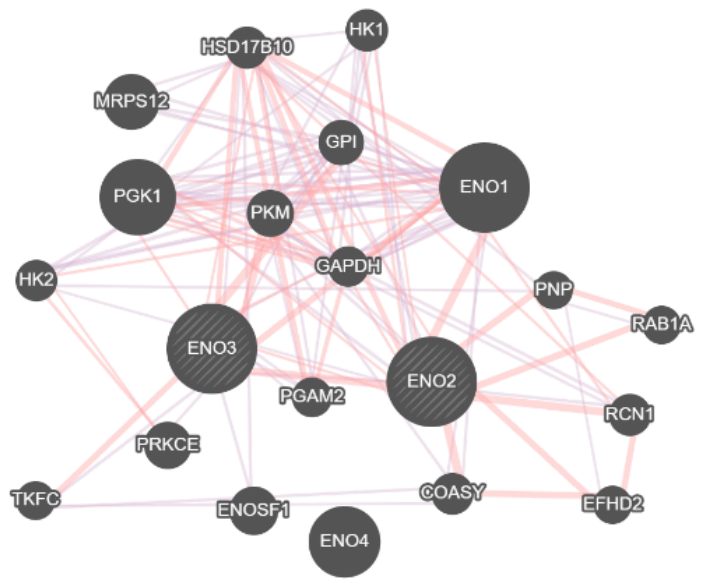

(E)

Figure 3. Gene interactions between the main functional proteins of synovial fluid. (A) showing the gene interactions of the DDWoR group. (B) showing the gene interactions of the MD group. (C) showing the gene interactions of the $\mathrm{CH}$ group. (D) showing the gene interactions of the DDWoR and MD group. (E) showing the gene interactions of the DDWoR, MD and CH group. 


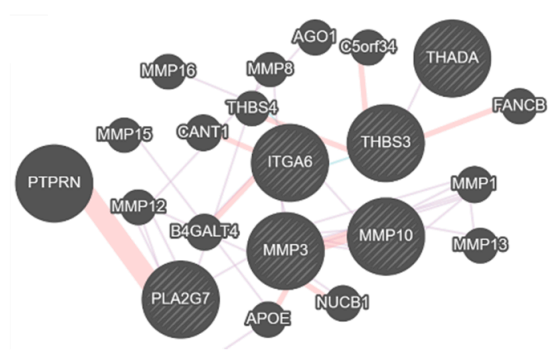

(A)

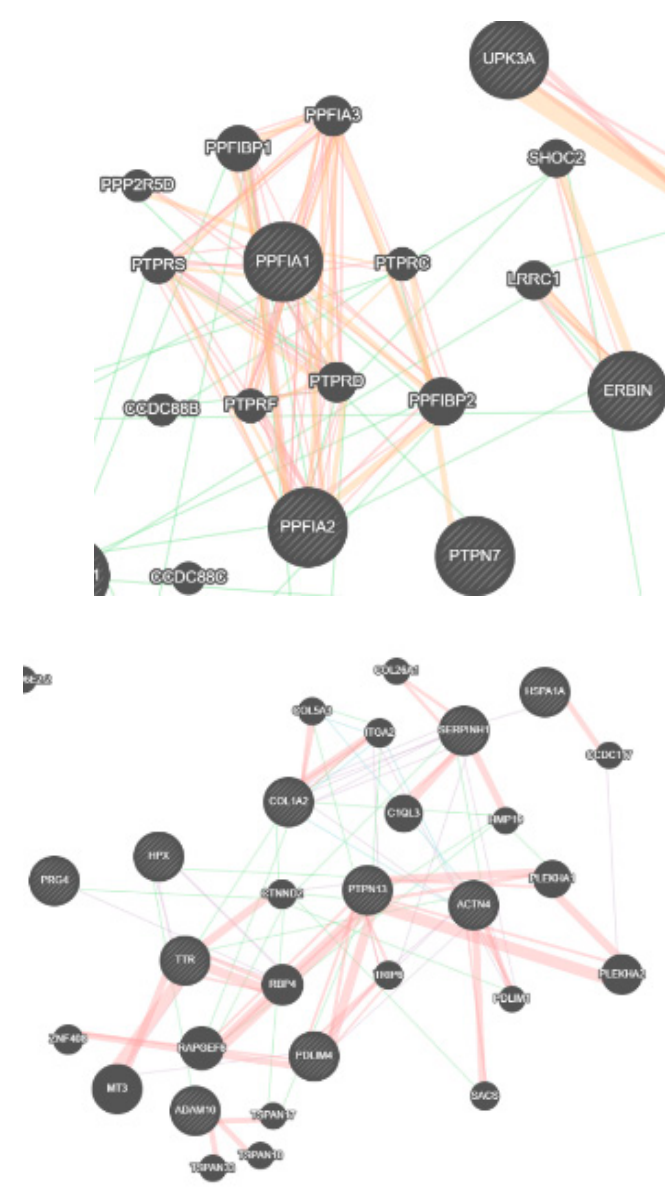

(C)

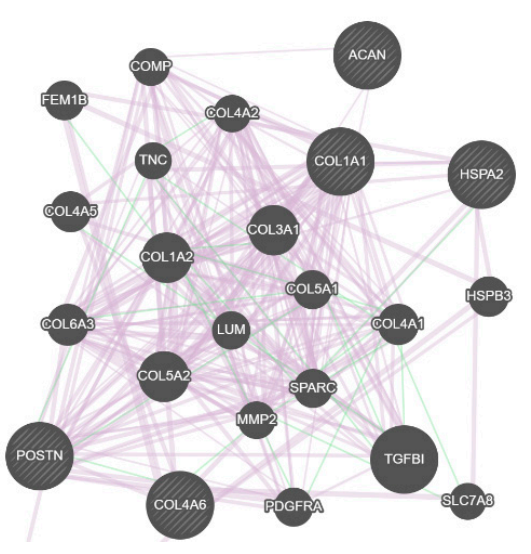

(E)

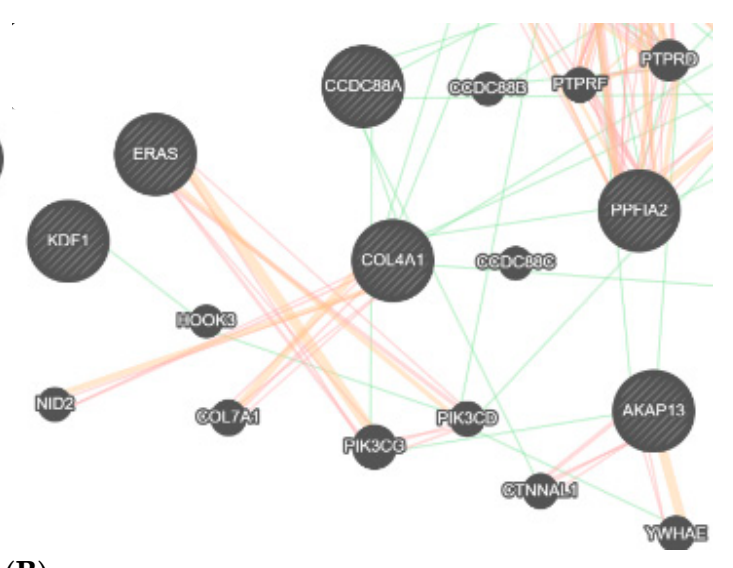

(B)

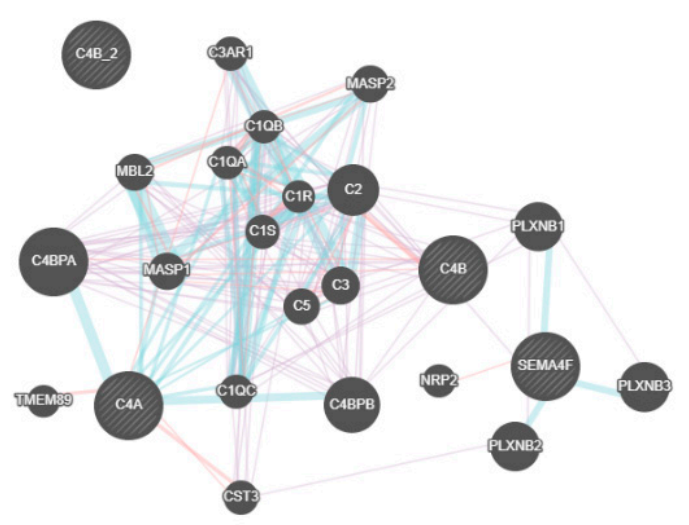

(D)

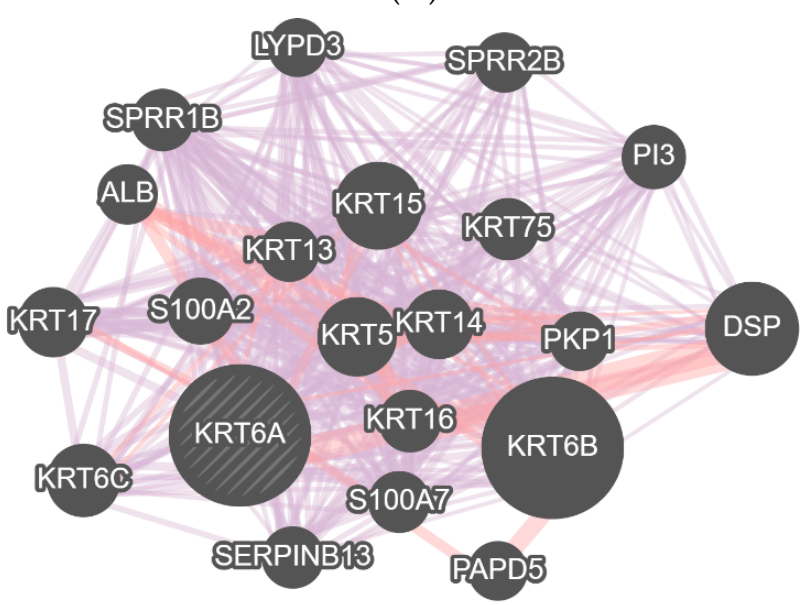

(F)

Figure 4. Cont. 


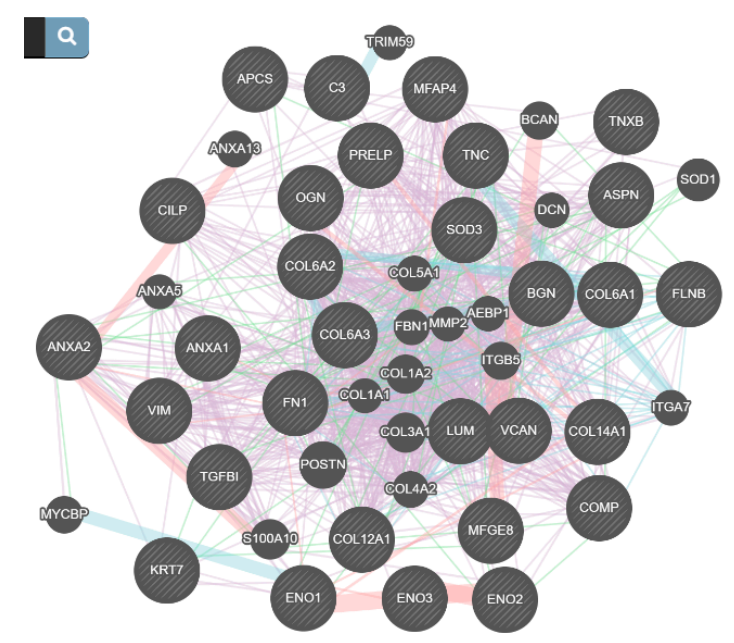

(G)

Figure 4. Gene interactions between the main functional proteins of the TMJ disc. (A) showing the gene interactions of the DDWoR group. (B) showing the gene interactions of the MD group. (C) showing the gene interactions of the $\mathrm{CH}$ group. (D) showing the gene interactions of the $\mathrm{CH}$ group. (E) showing the gene interactions of the DDWoR and $\mathrm{CH}$ group. (F) showing the gene interactions of the $\mathrm{MD}$ and $\mathrm{CH}$ group. $(\mathrm{G})$ showing the gene interactions of the DDWoR, MD and $\mathrm{CH}$ group.

The main proteins with important functions and networks that were identified in the synovial fluid sample were analyzed for each group (Figure 3). A brief description of these findings are: in the DDWoR group (Figure 3A) alpha-2-macroglobulin (A2M) involved in inflammatory process, amyloid P component (APCS) involved with apoptosis and complement factor $\mathrm{H}(\mathrm{CFH})$ that modulates inflammatory cascade were highlighted in the Genemania interaction figure; in the MD group (Figure 3B), hemopexin (HPX) involved in protection against oxidative stress was present; in the $\mathrm{CH}$ group (Figure $3 \mathrm{C}$ ), alcohol dehydrogenase subunit alpha (ADH1) that is responsible for alcohol degradation and interacts with growth hormone receptor (GHR) was present. In the group of DDWoR and MD (Figure 3D), annexin A1 (ANXA1), decorin (DCN), and immunoglobulin heavy constant gamma 1 (IGHG1) involved in inflammatory process, annexin A2 (ANXA2) involved with bone resorption, asporin (ASPN), biglycan (BGN), cartilage intermediate layer protein (CILP), osteoglycin (OGN), transforming growth factor beta induced (TGFBI) involved in bone and cartilage formation, fibronectin 1 (FN1), lumican (LUM) and tenascin XB (TNXB) involved in tissue repair, and neurofilament medium (NEFM) and thrombospondin 4 (THBS4) involved in neuropathic pain were included in the net. The DDWoR and $\mathrm{CH}$ group, and $\mathrm{MD}$ and $\mathrm{CH}$ group had no protein to be analyzed. The group with the three pathologies (DDWoR, MD and $\mathrm{CH}$ ) showed an interaction of enolase 2 (ENO2) and 3 (ENO3), involved in muscle regeneration (Figure 3E).

The disc sample presented the following protein interactions in Genemania (Figure 4): group DDWoR (Figure 4A) presented mainly the matrix metalloproteinase protein (MMP) family $(1,2,3,6,8,10,13,15,16)$, integrin subunit alpha 6 (ITGA6) and phospholipase A2 group VII (PLA2G7) that are involved in inflammatory cascade. Additionally, thrombospondin 3 (THBS3) and 4 (THBS4) involved in tissue remodeling, and THADA armadillo repeat containing (THADA) involved in apoptosis were present. In the MD group (Figure 4B), A-kinase anchor protein 13 (AKAP13), Erbin (ERBIN) and uroplakin-3a (UPK3A) involved in apoptosis, collagen alpha-1(IV) chain (COL4A1) and GTPase Eras (ERAS) involved in disc matrix constitution, and liprin-alpha-1 (PPFIA1) and (PPFIA2) 2 responsible for cell interactions were identified in the Genemania network. In the $\mathrm{CH}$ group (Figure $4 \mathrm{C}$ ), the present proteins were ADAM metallopeptidase domain 10 (ADAM10), that regulates apoptosis, collagen type I alpha 2 chain (COL1A2) and serpin family H member 1 (SERPINH1) involved in collagen formation, actinin alpha 4 (ACTN4), PDZ Additionally, LIM domain 4 (PDLIM4), transthyretin (TTR) and protein tyrosine phosphatase non-receptor type 13 
(PTPN13) involved in apoptosis, hormone modulation and bone formation. In the group of DDWoR and MD (Figure 4D), the complement C4A (C4A) and complement C4B (C4B) proteins that mediates the inflammatory process were identified. In the DDWoR and $\mathrm{CH}$ group (Figure 4E), mainly the proteins aggrecan (ACAN), collagen type I alpha 1 chain (COL1A1) and collagen type IV alpha 6 chain (COL4A6) that constitutes disc matrix, and periostin (POSTN) involved in wound healing were identified. In the MD and $\mathrm{CH}$ group (Figure 4F), keratin 6A (KRT6A) involved in wound healing was identified. Additionally, in the group with all three pathologies (DDWoR, MD and $\mathrm{CH}$ ) the proteins that interacted were annexin A1 (ANXA1), complement C3 (C3) and tenascin C (TNC) involved in inflammatory cascade modulation, annexin A2 (ANXA2) and transforming growth factor beta induced (TGFBI) involved in osteoclastogenesis, asporin (ASPN), biglycan (BGN), collagen type VI alpha 1 chain (COL6A1), osteoglycin (OGN) and vimentin (VIM) involved in chondrogenesis and osteogenesis, amyloid P component (APCS) and complement C3 (C3) in apoptosis and lumican (LUM) involved in tissue repair (Figure 4G).

\section{Discussion}

The different types of TMD may jeopardize patients' quality of life, masticatory function and have a great impact on health expenses. The identification of its multifactorial etiological components will enhance the employment of specific treatments, diminishing the hazard it causes in the TMJ. Therefore, the identification of the proteins expressed on each pathology group of this study (DDWoR, $\mathrm{MD}$, and $\mathrm{CH}$ ) might elucidate the cascades involved in the progression and severity of each TMD, leading to an assertive handling of TMD.

A total of 225 proteins were identified in the synovial fluid sample, and 379 in the TMJ disc sample (Table 2). It is important to highlight that the synovial fluid sample is very complex to obtain, therefore some proteins might not have been identified due to the technique that advocates the dilution of the synovial fluid. Nevertheless, the sample was collected according to worldwide employed standard methods previously described by other research groups [21,25]. Additionally, even though few proteins' expression might not have been observed, the expression of new proteins were identified for each pathology group, which enriches the global analysis of this study.

In our analysis, we found that all proteins expressed in the DDWoR group (synovial fluid and disc sample) (Tables 2 and 3) presented many proteins related to inflammatory process (MMP-3, -10, -27 in the disc sample) and apoptosis (mitogen-activated protein kinase 7-MAP3K7) and THADA in synovial fluid). Only the MMP-3 protein was previously associated with TMD [26,27]. These are proteins that highly impact the degeneration process in the TMJ of patients with DDWoR [26,28]. In the MD group, ERBIN protein was found in the disc sample, and it modulates TGFB, which was previously associated with TMJ degeneration [29]. Additionally, unprecedented proteins were seen in the synovial fluid associated with apoptosis (aldehyde dehydrogenase 1 family member L-ALDH1L1) and protection against oxidative stress (HPX), which probably helps diminish the mechanical overload consequences of the dislocation in the TMJ. Regarding $\mathrm{CH}$ proteins in the synovial fluid sample, ADH1 catalyzes the oxidation of alcohols to aldehydes, but as seen in Genemania (Figure 3C), it interacts with GHR, which might be involved with the condylar overgrowth. In a previous study, GHR has been injected in rabbits' TMJ to increase cartilage thickness [30], but it has not been studied as a possible etiology of condylar overgrowth yet.

Additionally, we also found a set of proteins to be common in both synovial fluid and disc samples (Table 4) in the groups DDWoR (chromodomain-helicase-DNA-binding protein 8 and myosin light chain 6B), MD (filamin A and liprin-alpha-1), and in the three groups (enolase 1, 2, 3, myosin heavy chain 16, ribosomal protein L7 like 1 and component of the shield in complex). These proteins were involved in cell matrix adhesion, cellular motor protein, reorganization of cytoskeleton, muscle development and regeneration. Additionally, another group of proteins were identified in both synovial fluid and disc 
samples (Table 7), being prevalent in all groups of disc samples. In the DDWoR and MD groups of synovial fluid samples, proteins implicated in apoptosis, inflammatory process, bone formation and resorption, chondrogenesis, wound healing, tissue repair and protection against oxidative stress were found. $\mathrm{CH}$ disc samples and MD synovial fluid samples presented, as common proteins, HPX (protection against oxidative stress) and SERPINC1 (biosynthetic pathway of collagen).

LUM is associated with the regulation of collagen fibers and with cell migration. In this study, LUM was present in all disc samples, and it has been pointed out to be elevated when the disc is under stress, as it enhances tissue repair [31]. Ulmner [32] reported that higher levels of LUM in synovial tissue might diminish TMD surgical success. On the other hand, TNC was present in all disc samples and in DDWoR and MD synovial fluid sample, being an important protein in wound healing [33].

Temporomandibular joint discs are fibrocartilaginous discs composed mainly by collagen, glycosaminoglycan and proteoglycans [34]. Studies in human adults and fetuses showed the expression of mainly collagen type I and III in TMJ discs, with type I collagen observed in the posterior band of the articular disc and collagen type III on the inferior surface of the articular disc [35,36]. Moreover, collagen type II synthesis was expressed on the external layer of the TMJ disc [37]. In this study, collagen type IV was identified in MD and $\mathrm{CH}$ samples (Table 8), and a previous study observed the presence of collagen type IV in the middle part of fetuses' TMJ disc, indicating the development of blood vessels [38]. The TMJ disc is an avascular tissue, although under stress it may undergo metaplasia, forming a vascularized fibrous tissue. Collagen type VII was present in all samples, and along with collagen type IV, it has chondroprotective effects against inflammation [39]. Collagen type XII and XIV were present in the disc samples of this study, which have never been identified in this region before in humans. A study identified collagen type XII only in bovine disc samples, which helps maintain collagen type I integrity [40]. Nevertheless, collagen type XIV was also observed in all TMJ disc samples, and it plays an essential structural role in the integrity of collagen type I, mechanical properties, organization, and shape of articular cartilage, which has never been described in the TMJ disc before [41]. This is important information to understand the composition's strength and weakness of the TMJ disc.

\section{Conclusions}

In conclusion, many proteins were identified for the first time in the TMJ disc and synovial fluid of the groups DDWoR, MD and $\mathrm{CH}$, leading to the enlightenment of each pathology's etiology, modulation and progression. Further studies with a greater sample are necessary to evaluate other proteins that might be present in these pathologies as well.

Author Contributions: Conceptualization: A.D.D., P.C.T., R.H.H.; methodology: A.D.D., P.C.T., R.H.H., M.A.R.B.; software: A.D.D., R.H.H., M.A.R.B.; validation: A.D.D., P.C.T., R.H.H., M.A.R.B.; formal Analysis: A.D.D., P.C.T., R.H.H., M.A.R.B.; investigation: A.D.D., P.C.T., R.H.H., M.A.R.B.; resources: A.D.D., P.C.T., R.H.H.; data curation: A.D.D., P.C.T., R.H.H., M.A.R.B.; writing-original draft preparation A.D.D., R.H.H.; writing-review and editing: A.D.D., P.C.T., R.H.H., M.A.R.B.; supervision: P.C.T., R.H.H., M.A.R.B.; project administration: A.D.D.; funding acquisition: A.D.D., P.C.T., R.H.H. All authors have read and agreed to the published version of the manuscript.

Funding: P.C.T. is supported by the National Council for Scientific and Technological Development, Chamada MCTIC/CNPq No 28/2018-Universal, Process: 426505/2018-2 for this research. R.H.H. is supported by Fundação Araucária (grant FA\#09/2016).

Institutional Review Board Statement: The study was conducted according to the guidelines of the Declaration of Helsinki, and approved by the Ethics Committee of Pontifical Catholic University of Paraná, Brazil, according to Resolution 196/96 of the National Health Council and approved under registration number 1.863.521, on the 20 May 2016.

Informed Consent Statement: Written informed consent was obtained from all subjects involved in the study. 
Data Availability Statement: Data is contained within the article.

Acknowledgments: We thank all individuals that were volunteers for agreeing to participate in this study. A.D.D. was supported by Fundação Araucária scholarship. P.C.T. is supported by the National Council for Scientific and Technological Development, Chamada MCTIC/CNPq N ${ }^{\circ}$ 28/2018 - Universal, Process: 426505/2018-2 for this research. R.H.H. is supported by Fundação Araucária (grant FA\#09/2016). We thank Alexandra Senegaglia and Paulo R. S. Brofman for the laboratory support at Pontifícia Universidade Católica do Paraná, Brazil.

Conflicts of Interest: The authors declare no conflict of interest.

\section{References}

1. Slade, G.D.; Ohrbach, R.; Greenspan, J.D.; Fillingim, R.B.; Bair, E.; Sanders, A.E.; Dubner, R.; Diatchenko, L.; Meloto, C.B.; Smith, S.; et al. Painful Temporomandibular Disorder: Decade of Discovery from OPPERA Studies. J. Dent. Res. 2016, 95, 1084-1092. [CrossRef]

2. National Institute of Health. Available online: https:/ / www.nidcr.nih.gov/health-info/tmj (accessed on 3 October 2019).

3. Ohrbach, R.; Dworkin, S.F. The Evolution of TMD Diagnosis: Past, Present, Future. J. Dent. Res. 2016, 95, 1093-1101. [CrossRef]

4. Minervini, G.; Lucchese, A.; Perillo, L.; Serpico, R.; Minervini, G. Unilateral superior condylar neck fracture with disloca-tion in a child treated with an acrylic splint in the upper arch for functional repositioning of the mandible. Case Rep. Cranio 2017, 35, 337-341.

5. Eberhard, D.; Bantleon, H.; Steger, W. The efficacy of anterior repositioning splint therapy studied by magnetic resonance imaging. Eur. J. Orthod. 2002, 24, 343-352. [CrossRef]

6. Supplement, D.; Minervini, G.; Nucci, L.; Lanza, A.; Femiano, F.; Contaldo, M.; Grassia, V. Temporomandibular disc displacement with reduction treated with anterior repositioning splint: A 2-year clinical and magnetic resonance imaging (MRI) follow-up. Case Rep. J. Biol. Regul. Homeost. Agents 2020, 34, 151-160.

7. Talaat, W.M.; Adel, O.I.; Al Bayatti, S. Prevalence of temporomandibular disorders discovered incidentally during routine dental examination using the Research Diagnostic Criteria for Temporomandibular Disorders. Oral Surg. Oral Med. Oral Pathol. Oral Radiol. 2018, 125, 250-259. [CrossRef] [PubMed]

8. Cakarer, S.; Isler, S.; Yalcin, B.; Şitilci, T. Management of the bilateral chronic temporomandibular joint dislocation. Ann. Maxillofac. Surg. 2018, 8, 154. [CrossRef] [PubMed]

9. Poluha, R.L.; Canales, G.D.L.T.; Costa, Y.M.; Grossmann, E.; Bonjardim, L.R.; Conti, P.C.R. Temporomandibular joint disc displacement with reduction: A review of mechanisms and clinical presentation. J. Appl. Oral Sci. 2019, 27, e20180433. [CrossRef]

10. Fayed, M.M.S.; El-Mangoury, N.H.; El-Bokle, D.N.; Belal, I.A. Occlusal splint therapy and magnetic resonance imaging. World J. Orthod. 2004, 5, 133-140.

11. Prechel, U.; Ottl, P.; Ahlers, O.M.; Neff, A. The Treatment of Temporomandibular Joint Dislocation: A Systematic Review. Dtsch. Arztebl. Int. 2018, 115, 59-64.

12. Nitzan, D.W.; Katsnelson, A.; Bermanis, I.; Brin, I.; Casap, N. The clinical characteristics of condylar hyperplasia: Expe-rience with 61 patients. J. Oral Maxillofac. Surg. 2008, 66, 312-318. [CrossRef] [PubMed]

13. Raijmakers, P.G.; Karssemakers, L.H.; Tuinzing, D.B. Female Predominance and Effect of Gender on Unilateral Condylar Hyperplasia: A Review and Meta-Analysis. J. Oral Maxillofac. Surg. 2012, 70, 72-76. [CrossRef]

14. Mahajan, M. Unilateral condylar hyperplasia-A genetic link? Case reports. Nat. J. Maxillofacial Surg. 2017, 8, 58-63. [CrossRef]

15. Herr, M.M.; Fries, K.M.; Upton, L.G.; Edsberg, L.E. Potential Biomarkers of Temporomandibular Joint Disorders. J. Oral Maxillofac. Surg. 2011, 69, 41-47. [CrossRef] [PubMed]

16. Demerjian, G.G.; Sims, A.B.; Stack, B.C. Proteomic signature of Temporomandibular Joint Disorders (TMD): Toward di-agnostically predictive biomarkers. Bioinformation 2011, 6, 282-284. [CrossRef] [PubMed]

17. DuPree, E.J.; Jayathirtha, M.; Yorkey, H.; Mihasan, M.; Petre, B.A.; Darie, C.C. A Critical Review of Bottom-Up Proteomics: The Good, the Bad, and the Future of this Field. Proteomes 2020, 8, 14. [CrossRef] [PubMed]

18. Murphy, M.K.; MacBarb, R.F.; Wong, M.E.; Athanasiou, K.A. Temporomandibular Joint Disorders: A Review of Etiology, Clinical Management, and Tissue Engineering Strategies. Int. J. Oral Maxillofac. Implant. 2013, 28, 393-414. [CrossRef] [PubMed]

19. Olate, S.; Netto, H.D.; Rodriguez-Chessa, J.; Alister, J.P.; Albergaria-Barbosa, J.P.; de Moraes, J. Mandible condylar hy-perplasia: A review of diagnosis and treatment protocol. Int J. Clin. Exp. Med. 2013, 6, 727-737. [PubMed]

20. Mehra, P.; Wolford, L.M. Serum nutrient deficiencies in the patient with complex temporomandibular joint problems. Bayl. Univ. Med. Cent. Proc. 2008, 21, 243-247. [CrossRef]

21. Alstergren, P.; Benavente, C.; Kopp, S. Interleukin-1beta, interleukin-1 receptor antagonist, and interleukin-1 soluble receptor II in temporomandibular joint synovial fluid from patients with chronic polyarthritides. J. Oral Maxillofac. Surg. 2003, 61, 1171-1178. [CrossRef]

22. Cassiano, L.P.; Ventura, T.M.; Silva, C.M.; Leite, A.L.; Magalhães, A.C.; Pessan, J.P.; Buzalaf, M.A.R. Protein Profile of the Acquired Enamel Pellicle after Rinsing with Whole Milk, Fat-Free Milk, and Water: An in vivo Study. Caries Res. 2018, 52, 288-296. [CrossRef]

23. Universal Protein Resource. Available online: http://www.uniprot.org (accessed on 5 September 2020). 
24. Warde-Farley, D.; Donaldson, S.L.; Comes, O.; Zuberi, K.; Badrawi, R.; Chao, P.; Franz, M.; Grouios, C.; Kazi, F.; Lopes, C.T.; et al. The GeneMANIA prediction server: Biological network integration for gene prioritization and predicting gene function. Nucleic Acids Res. 2010, 38, 214-220. [CrossRef]

25. Fredriksson, L.; Alstergren, P.; Kopp, S. Tumor Necrosis Factor- $\alpha$ in Temporomandibular Joint Synovial Fluid Predicts Treatment Effects on Pain by Intra-Articular Glucocorticoid Treatment. Mediat. Inflamm. 2006, 2006, 59425. [CrossRef]

26. Fujita, H.; Morisugi, T.; Tanaka, Y.; Kawakami, T.; Kirita, T.; Yoshimura, Y. MMP-3 activation is a hallmark indicating an early change in TMJ disorders, and is related to nitration. Int. J. Oral Maxillofac. Surg. 2009, 38, 70-78. [CrossRef]

27. Tilikainen, P.; Pirttiniemi, P.; Kainulainen, T.; Pernu, H.; Raustia, A. MMP-3 and -8 expression is found in the condylar surface of temporomandibular joints with internal derangement. J. Oral Pathol. Med. 2005, 34, 39-45. [CrossRef] [PubMed]

28. Loreto, C.; Filetti, V.; Almeida, L.E.; Rosa, G.R.; Leonardi, R.; Grippaudo, C.; Giudice, A. MMP-7 and MMP-9 are over-expressed in the synovial tissue from severe temporomandibular joint dysfunction. Eur. J. Histochem. 2020, 64, 3113. [CrossRef]

29. Da Costa, G.F.A.; Souza, R.D.C.; de Araújo, G.M.; Gurgel, B.C.V.; Barbosa, G.A.S.; Calderon, P.D.S. Does TGF-beta play a role in degenerative temporomandibular joint diseases? A systematic review. Cranio 2017, 35, 228-232. [CrossRef] [PubMed]

30. Ulmner, M.; Sugars, R.; Naimi-Akbar, A.; Tudzarovski, N.; Kruger-Weiner, C.; Lund, B. Synovial Tissue Proteins and PatientSpecific Variables as Predictive Factors for Temporomandibular Joint Surgery. Diagnostics 2020, 11, 46. [CrossRef] [PubMed]

31. Feizbakhsh, M.; Razavi, M.; Minaian, M.; Teimoori, F.; Dadgar, S.; Maghsoodi, S. The effect of local injection of the human growth hormone on the mandibular condyle growth in rabbit. Dent. Res. J. 2014, 11, 436-441.

32. Koyama, E.; Saunders, C.; Salhab, I.; Decker, R.; Chen, I.; Um, H.; Pacifici, M.; Nah, H. Lubricin is Required for the Structural Integrity and Post-natal Maintenance of TMJ. J. Dent. Res. 2014, 93, 663-670. [CrossRef] [PubMed]

33. Stocum, D.L.; Roberts, W.E. Part I: Development and Physiology of the Temporomandibular Joint. Curr. Osteoporos. Rep. 2018, 16, 360-368. [CrossRef]

34. Berkovitz, B.K.B.; Holland, G.R.; Moxham, B.J. Oral Anatomy, Histology and Embryology, 4th ed.; Mosby: St. Louis, MD, USA, 2009.

35. Gage, J.; Virdi, A.; Triffitt, J.; Howlett, C.; Francis, M. Presence of type III collagen in disc attachments of human temporomandibular joints. Arch. Oral Biol. 1990, 35, 283-288. [CrossRef]

36. De Moraes, L.O.; Lodi, F.R.; Gomes, T.S.; Marques, S.R.; Oshima, C.T.; Lancellotti, C.L.; Rodríguez-Vázquez, J.F.; Mé-rida-Velasco, J.R.; Alonso, L.G. Immunohistochemical expression of types I and III collagen antibodies in the tem-poromandibular joint disc of human foetuses. Eur. J. Histochem. 2011, 55, 24. [CrossRef]

37. Kondoh, T.; Hamada, Y.; Iino, M.; Takahashi, T.; Kikuchi, T.; Fujikawa, K.; Seto, K. Regional differences of type II collagen synthesis in the human temporomandibular joint disc: Immunolocalization study of carboxy-terminal type II procollagen peptide (chondrocalcin). Arch. Oral Biol. 2003, 48, 621-625. [CrossRef]

38. De Moraes, L.O.; Lodi, F.R.; Gomes, T.S.; Marques, S.R.; Fernandes Junior, J.A.; Oshima, C.T.; Alonso, L.G. Immuno-histochemical expression of collagen type IV antibody in the articular disc of the temporomandibular joint of human fe-tuses. Ital. J. Anat. Embryol. 2008, 113, 91-95. [PubMed]

39. Chu, W.C.; Zhang, S.; Sng, T.J.; Ong, Y.J.; Tan, W.-L.; Ang, V.Y.; Foldager, C.B.; Toh, W.S. Distribution of pericellular matrix molecules in the temporomandibular joint and their chondroprotective effects against inflammation. Int. J. Oral Sci. 2017, 9, 43-52. [CrossRef] [PubMed]

40. Deng, M.H.; Xu, J.; Cai, H.X.; Fang, W.; Long, X. Effect of temporomandibular joint disc perforation on expression of type ? collagen in temporomandibular joint disc cells. Chin. J. Stomatol. 2017, 52, 274-277.

41. Ciavarella, D.; Mastrovincenzo, M.; Sabatucci, A.; Campisi, G.; Di Cosola, M.; Suriano, M.; Muzio, L.L. Primary and secondary prevention procedures of temporo-mandibular joint disease in the evolutive age. Minerva Pediatr. 2009, 61, 93-97. 